\title{
The Scripps Coupled Ocean-Atmosphere Regional (SCOAR) Model, with Applications in the Eastern Pacific Sector
}

\author{
Hyodae Seo, Arthur J. Miller, and John O. Roads \\ Scripps Institution of Oceanography, La Jolla, California
}

(Manuscript received 28 October 2005, in final form 13 June 2006)

\begin{abstract}
A regional coupled ocean-atmosphere model is introduced. It is designed to admit the air-sea feedbacks arising in the presence of an oceanic mesoscale eddy field. It consists of the Regional Ocean Modeling System (ROMS) and the Regional Spectral Model (RSM). Large-scale forcing is provided by NCEP/DOE reanalysis fields, which have physics consistent with the RSM. Coupling allows the sea surface temperature (SST) to influence the stability of the atmospheric boundary layer and, hence, the surface wind stress and heat flux fields. The system is denominated the Scripps Coupled Ocean-Atmosphere Regional (SCOAR) Model.

The model is tested in three scenarios in the eastern Pacific Ocean sector: tropical instability waves of the eastern tropical Pacific, mesoscale eddies and fronts of the California Current System, and gap winds of the Central American coast. Recent observational evidence suggests air-sea interactions involving the oceanic mesoscale in these three regions. Evolving SST fronts are shown to drive an unambiguous response of the atmospheric boundary layer in the coupled model. This results in significant model anomalies of wind stress curl, wind stress divergence, surface heat flux, and precipitation that resemble the observations and substantiate the importance of ocean-atmosphere feedbacks involving the oceanic mesoscale.
\end{abstract}

\section{Introduction}

Increased interest in ocean-atmosphere interaction on spatial scales associated with the oceanic mesoscale has arisen because of new enhanced views of the global ocean and atmosphere from satellite remote sensing. Two extensive reviews by Chelton et al. (2004) and Xie (2004) describe numerous efforts to understand these observations of mesoscale air-sea coupling processes throughout the World Ocean.

The close associations among ocean states [sea surface temperature (SST), currents, and thermocline depth], atmospheric states (surface winds, cloudiness, and rainfall), surface flux components (wind stress, heat flux, and freshwater flux), and geography (orography, coastlines, bathymetry, and islands) on various space and time scales are common features worldwide. Radar scatterometry and microwave imagers now provide daily estimates of wind, SST, and rainfall over $90 \%$ of

Corresponding author address: Hyodae Seo, Climate Research Division, Scripps Institution of Oceanography, La Jolla, CA 92093-0224.

E-mail: hyseo@ucsd.edu the global ocean with remarkable accuracy (Chelton and Wentz 2005; Wentz and Meissner 2000; Chelton and Freilich 2005). This has stimulated air-sea interaction studies and unveiled various aspects of climatically important air-sea interaction processes. Current largescale global analyses of the atmosphere and ocean, however, have inadequate resolution to resolve the sharp transitions of SST fronts or realistic coastal mountain ranges. Understanding the mechanisms of air-sea coupling therefore has been limited, especially in such regions.

This new information from satellites has now started to serve as a validation benchmark for the high-resolution global coupled model studies. Sakamoto et al. (2004), for example, used the high-resolution atmosphere-ocean coupled general circulation model run on Japan's Earth Simulator to successfully reproduce the far-reaching influences of the Hawaiian Islands. This verified the hypothesis by Xie et al. (2001), based on the observations, that disturbances of SST, wind, and cloudiness in the wake of the Hawaiian Islands are caused by island-induced wind stress curl.

Although global coupled models are beginning to increase their resolution to attempt to resolve smaller- 
scale processes, high-resolution regional coupled ocean-atmosphere models, if properly driven by the large-scale circulation, could provide additional advantages in the study of the detailed patterns of air-sea interactions involving oceanic mesoscale eddies, including meanders. By concentrating most of the computational resources in spatial resolution and detailed parameterizations, small-scale processes may be effectively and optimally isolated and studied.

A high-resolution regional coupled ocean-atmosphere model has been developed with this approach in mind. The system is denominated the Scripps Coupled Ocean-Atmosphere Regional (SCOAR) model. The goal in this paper is to introduce the model and demonstrate its basic performance capabilities in the eastern Pacific Ocean. The spatial and temporal patterns of air-sea interaction in the model are found to be similar to those observed in three unique regions of the eastern Pacific sector.

Additional efforts are now in progress to test various hypotheses of regional air-sea interactions proposed by numerous investigators. For example, the model is capable of producing more realistic mean features of the tropical Atlantic climate by resolving ocean mesoscale features, such as tropical instability waves (TIWs) and coastal upwelling (Seo et al. 2006). Other key questions to be addressed in this modeling framework include: How do the turbulent fluxes contribute to the evolving SST? How do SST-induced wind stress perturbations affect dynamical stability properties of the ocean? $\mathrm{Fu}$ ture work will involve more rigorous and quantitative analysis to carefully compare with the observations and also render the regional coupled modeling system capable for hindcasting, nowcasting, and forecasting experiments.

In section 2, some previous regional coupled modeling studies are summarized. In section 3, each component of the SCOAR Model is introduced. In section 4, three examples of the coupled model simulations are discussed, followed by the summary and discussion in section 5 .

\section{Regional coupled modeling background}

There have been a growing number of attempts in the past decade to develop regional coupled oceanatmosphere models with various goals in several parts of the globe. These previous studies are summarized here.

Early progress in building a regional coupled model was made as a major element within the Baltic Sea Experiment. In that effort, Gustafsson et al. (1998) coupled a high-resolution atmospheric model to a low- resolution ice-ocean model for the purpose of accurate weather forecasting in the Baltic Sea. Hagedorn et al. (2000) coupled the Max Plank Institute (MPI) Regional Atmospheric Model (REMO) to the 3D Kiel ocean model in the same Baltic area. The model SST improved even without flux correction, although the improvement was limited to summertime because the sea ice modeling component was incomplete. Schrum et al. (2003) achieved full flux coupling using the same atmospheric model coupled to the 3D Hamburg Ocean Model. They showed that their interactively coupled ocean-atmosphere runs were stable and distinctively better than atmospheric runs with prescribed SST. Döscher et al. (2002) developed a regional coupled ocean-atmosphere-ice model (RCAO) with the aim of simulating regional coupled climate scenarios over northern Europe based on multiyear hindcasts.

More advanced high-resolution coupled model studies using the REMO coupled to a global MPI ocean model are being used to study the effect of air-sea coupling on Indonesian rainfall (Aldrian et al. 2005) and interannual variability of sea ice extent in the Arctic Ocean and "Nordic Seas" (Mikolajewicz et al. 2005).

Another motivation for developing regional coupled modeling system is to study the effect of the surface state of the ocean or lakes (e.g., surface waves, surface roughness) on atmospheric circulation. One example of such a study is Powers and Stoelinga (2000). They developed a comprehensive atmosphere-ocean-wave coupled modeling system and performed sensitivity tests on the surface roughness parameterization of the atmospheric model [fifth-generation Pennsylvania State University-National Center for Atmospheric Research (NCAR) Mesoscale Model (MM5)] for the case of frontal passage over the Lake Erie region. They showed that a marine roughness parameterization that takes into account the wave age from the wave model can significantly improve the calculation of surface wind stress and heat flux.

A high-resolution regional air-sea coupled model including ocean waves is also useful in studying the effect of sea spray, wind-induced mixing, and surface wave fields on simulating the intensity and evolution of hurricanes for both research and operational purposes (Bao et al. 2000; Li and Xue 2002; Bender and Ginis 2000; Perrie et al. 2004; Chen et al. 2007; among many others). A regional coupled model also has been shown to be useful in simulating the East Asia summer monsoon (Ren and Qian 2005) despite the presence of a cold drift in SST in their model.

A coupled model is also valuable for studying extreme weather events in the Adriatic Sea region. 
Loglisci et al. (2004) applied their coupled model to studying the effect of a bora wind event on the dynamics and thermodynamics in the Adriatic Sea. They found that accurate heat flux from the sea surface needs to be considered for better representation of air-sea interactions associated with this high wind event and for improved simulations of SSTs in the response. However, their climatological initialization for the ocean model generated systematic errors in SST. More recently, Pullen et al. (2006) established a regional coupled system comprising the Navy Coastal Ocean Model (NCOM) coupled to the Coupled Ocean-Atmosphere Mesoscale Prediction System (COAMPS) in the same region. They focused on the coupled effects of fine-resolution SST on air properties, in particular during the course of a bora wind event. They found that the simulated SST after a bora event had a stabilizing effect on the atmosphere, thus reducing atmospheric boundary layer mixing and yielding more skillful near-surface winds.

Now regional coupled models are beginning to be used for studying basin-scale climate simulations. Huang et al. (2004) applied a regional coupling strategy in a global coupled ocean-atmosphere GCM, where active air-sea coupling is allowed only in the Atlantic Ocean basin. The study showed that this regional coupling strategy allowed them to isolate the effects of local feedbacks on the resulting mean SST. Xie et al. (2007) constructed the regional ocean-atmosphere coupled system (iROAM) which couples a regional atmospheric model (iRAM) to a basin-scale ocean model in the Pacific, with interactive coupling permitted only in the eastern half of the basin. A major advantage of iROAM is that by affording reasonably high resolution to the model $\left(0.5^{\circ}\right.$ in the atmosphere and ocean $)$ compared to most coupled GCMs, it can effectively explore the role of local air-sea feedbacks arising from ocean mesoscale features and land topography while allowing significant internal coupled variability free from the prescribed lateral boundary conditions. It is specifically designed to study processes and reduce biases in the eastern tropical Pacific climate, where many coupled GCMs exhibit common problems.

As we shall see in the next section, the uniqueness of the SCOAR Model compared to many of these coupled models is that it has greater portability, more complete coupling, parallel architecture, state-of-the-art physics, and dynamical consistency with the National Centers for Environmental Prediction (NCEP) reanalysis forcing. The three eastern Pacific examples discussed in section 4, together with the Atlantic domain used by Seo et al. (2006), demonstrate that the model can be set up anywhere in the World Ocean at any chosen resolution. This portability, together with the SCOAR
Model's flexible coupling processes, ability to run on massively parallel computers, sophisticated physical parameterizations, and realistic large-scale forcing yields a great potential for the SCOAR Model to be applied throughout the World Ocean for numerous scientific goals.

The main target of the SCOAR Model is to study the fundamental nature of ocean-atmosphere feedbacks on the ocean mesoscale in hindcasts. Hence, the current modeling system does not include any operational forecasting framework or data assimilation components to produce skillful predictions. Nevertheless, the use of the SCOAR model for operational and/or forecasting purposes (Wilkin et al. 2005), including data assimilation (Moore et al. 2004), is part of our long-term plans.

\section{The SCOAR Model}

\section{a. RSM atmospheric model}

The atmospheric component of the coupled model is the Experimental Climate Predictions Center (ECPC) Regional Spectral Model (RSM). The RSM was originally developed by Juang and Kanamitsu (1994) and underwent frequent improvements and updates to its functionality, efficiency, and dynamics and physics (Juang et al. 1997). Briefly, the RSM used here is a regional extension to the Global Spectral Model (GSM) used in the NCEP/Department of Energy (DOE) Reanalysis (RA2; Kanamitsu et al. 2002a).

The RSM is a primitive-equation hydrostatic model on terrain-following sigma coordinates, and the largescale (low wavenumber) components of the flow are specified in the model by the RA2 downscaling procedure or by any GSM simulation. Numerous sensitivity studies (e.g., Roads et al. 2003) demonstrate the excellent performance of the RSM, which has a significantly greater freedom to respond to internal dynamics compared with other regional models. The RSM boundary layer physics employs a nonlocal diffusion concept (Hong and Pan 1996). This scheme is strongly coupled to the surface layer physics. In the scheme, the turbulent diffusivity coefficients are calculated from a prescribed profile shape as a function of boundary layer height and scale parameters derived from similarity requirements. Above the mixed layer, a local diffusion approach is applied to account for free atmospheric diffusion. The parameterization for deep convection is based on the Relaxed Arakawa-Schubert Scheme (Arakawa and Schubert 1974; Moorthi and Suarez 1992). Further details about the model physics can be found in Kanamitsu et al. (2002b). 


\section{b. ROMS ocean model}

The oceanic part of the coupled model is the Regional Ocean Modeling System (ROMS). The ROMS solves the incompressible and hydrostatic primitive equations with a free surface on horizontal curvilinear coordinates and utilizes stretched generalized sigma coordinates in order to enhance vertical resolution near the sea surface and bathymetry (Haidvogel et al. 2000; Shchepetkin and McWilliams 2005). A radiation method is used along the open boundaries in order to allow for stable, long-term integrations together with a flow-adaptive nudging term for relaxation toward the prescribed lateral boundary conditions. That is, the nudging is stronger (time scale of 1 day) if the flow is inward and weaker (time scale of $1 \mathrm{yr}$ ) for outflow (Marchesiello et al. 2001). Implicit diffusivity associated with third-order upstream horizontal advection is used in the lateral plane as opposed to explicit diffusivity. Mixed layer dynamics are parameterized using a Kprofile parameterization (KPP) scheme (Large et al. 1994), with a vertical mixing coefficient of $10^{-5} \mathrm{~m}^{2} \mathrm{~s}^{-1}$ (Shchepetkin and McWilliams 2005). In all three examples in section 4, 20 vertical sigma layers are used, with approximately 10 layers in the upper $100 \mathrm{~m}$ in the open ocean.

The lateral boundary conditions (BCs) that force ROMS are provided either from the ocean analysis from the Estimating the Circulations and the Climate of the Ocean Project, or from climatological mean temperature and salinity (Levitus and Boyer 1994; Levitus et al. 1994). The latter is more appropriate for studying an equilibrium structure of ocean currents (e.g., Marchesiello et al. 2003; Di Lorenzo 2003; Di Lorenzo et al. 2005), while the former is preferred for retrospective simulations.

\section{c. Flux-SST coupler}

To build a coupled modeling system, a flux-SST coupler that bridges the atmospheric model (RSM) and ocean model (ROMS) needed to be constructed (Fig. 1 ). The coupler currently works in a sequential fashion; the RSM and ROMS take turns integrating while exchanging forcing. The interacting boundary layer between RSM and ROMS is based on either RSM's boundary layer physics package, or the bulk formula that is implemented in ROMS. The former calculates forcing fields necessary to drive ROMS based on the nonlocal boundary layer scheme described in section 3a. The latter computes surface fluxes of momentum, sensible heat, and latent heat from near-surface meteorological variables based on Fairall et al. (1996), adapted from the Coupled Ocean-Atmosphere Re-

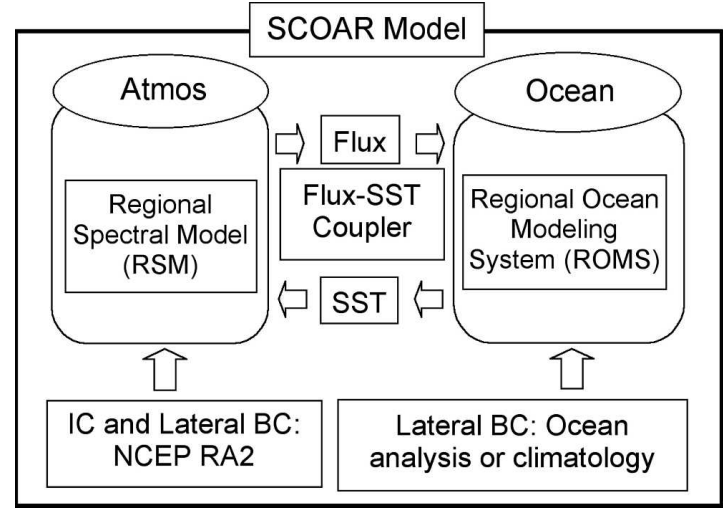

FIG. 1. Schematic description of the SCOAR Model; initialization and large-scale atmospheric flows specified as low-wavenumber forcing of the RSM are obtained from RA2. Initial and boundary conditions for ROMS are from the ocean analysis from the Estimating the Circulations and the Climate of the Ocean (ECCO) project, or Levitus climatological mean temperature and salinity. The RSM and ROMS are coupled sequentially with typical coupling intervals of 3,24 , or $120 \mathrm{~h}$.

sponse Experiment (COARE) algorithm. For all model applications in section 4 , a bulk parameterization is used at the air-sea interface. ROMS then forces the RSM at the lower boundary by providing SST. Various coupling intervals can be specified in the coupler $(3,24$, or $120 \mathrm{~h}$, and so on), depending on the interaction time scales of interest. In each experiment discussed below, 24-h coupling is used.

Both atmospheric and ocean models conventionally assume that atmospheric wind stress imposed on the sea surface is a function of atmospheric wind only. This is often justified owing to the fact that ocean current speed is typically small compared to the wind speed by order of magnitude. The corresponding conventional parameterization for wind stress in that case is $\tau=$ $\rho C_{d}\left|U_{a}\right| U_{a}$, where $\rho$ is air density, $C_{d}$ is drag constant, and $U_{a}$ is wind speed at $10-\mathrm{m}$ heights. However, the importance of surface current in the estimation of surface wind stress (Bye 1986) has been noted in several observational studies (e.g., Kelly et al. 2001; Cornillon and Park 2001; Park et al. 2006) using the Quick Scatterometer (QuikSCAT), which measures wind velocity relative to the ocean surface velocity. Furthermore, Chelton et al. (2004) showed that narrow and intense ocean currents such as the Gulf Stream and Kuroshio exert a strong influence on wind stress curl fields [cf. Behringer et al. (1979), who showed that SST in these regions strongly influences wind stress curl].

Wind stress in SCOAR is therefore calculated by taking into account the relative motion of wind and ocean current using $\tau=\rho C_{d}\left|U_{a}-U_{o}\right|\left(U_{a}-U_{o}\right)$, where $U_{o}$ denotes ocean current speed. The importance of this 
TABLE 1. Model domain specifications for the eastern tropical Pacific, Central American coast, and California Curent System. For all experiments, RSM (ROMS) uses 28 (20) vertical layers. The ETC and CAC cases are 5-yr simulations from 1999 to 2003 , while the CCS case is 4 years from 2001 to 2004.

\begin{tabular}{|c|c|c|c|c|}
\hline \multirow[b]{2}{*}{ Application } & \multicolumn{2}{|c|}{ RSM } & \multicolumn{2}{|c|}{ ROMS } \\
\hline & $\begin{array}{l}\text { Horizontal } \\
\text { resolution } \\
(\mathrm{km})\end{array}$ & $\begin{array}{l}\text { Grid size } \\
(N x \times N y)\end{array}$ & $\begin{array}{l}\text { Horizontal } \\
\text { resolution } \\
\quad(\mathrm{km})\end{array}$ & $\begin{array}{c}\text { Grid size } \\
(N x \times N y)\end{array}$ \\
\hline ETP & 50 & $129 \times 86$ & 42 & $147 \times 88$ \\
\hline CCS & 16 & $107 \times 120$ & 7 & $220 \times 250$ \\
\hline CAC & 27 & $129 \times 86$ & 25 & $138 \times 82$ \\
\hline
\end{tabular}

parameterization is supported by the recent study of Luo et al. (2005), who showed that allowing momentum exchange between the surface ocean currents and wind in their coupled GCM could effectively reduce the familiar cold SST bias in the equatorial ocean. Dawe and Thompson (2006) reported a similar result. Duhaut and Straub (2006) further demonstrated with a scaling argument and a simple modeling study that the perturbation to the wind stress due to ocean currents could lead to substantial changes in the curl of wind stress. This is because the spatial scale associated with ocean current is much smaller than that of wind speed. It should also be noted that we assume the effect of the surface gravity wave on the sea state is negligible.

Since the grids of the atmosphere and ocean models are generally different, a simple linear interpolation is used to map the SST and ocean currents to the atmospheric physical space grid and the resultant fluxes to the ocean grid. Care must be taken in choosing the land-sea mask near the coasts because the atmospheric model is spectral and Gibbs phenomena can result in unphysical structures in the surface flux forcing fields over the oceanic grid points adjacent to the coast. In each example domain to be discussed next, the landsea mask was qualitatively optimized to reduce this effect of the mismatch between spectral atmospheric and physical space oceanic models.

\section{Examples of SCOAR model simulations}

Three different model domains are examined to test the SCOAR model performance and capabilities. These include the eastern tropical Pacific (ETP), the California Current System (CCS), and the Central American coast (CAC). The ETP contains TIWs, the CCS provides examples of midlatitude mesoscale eddy feedbacks, and the CAC allows gap winds to drive ocean mesoscale structures. Table 1 summarizes the resolution used in these domains, and Fig. 2 shows the model bathymetry and orography for each case. In each

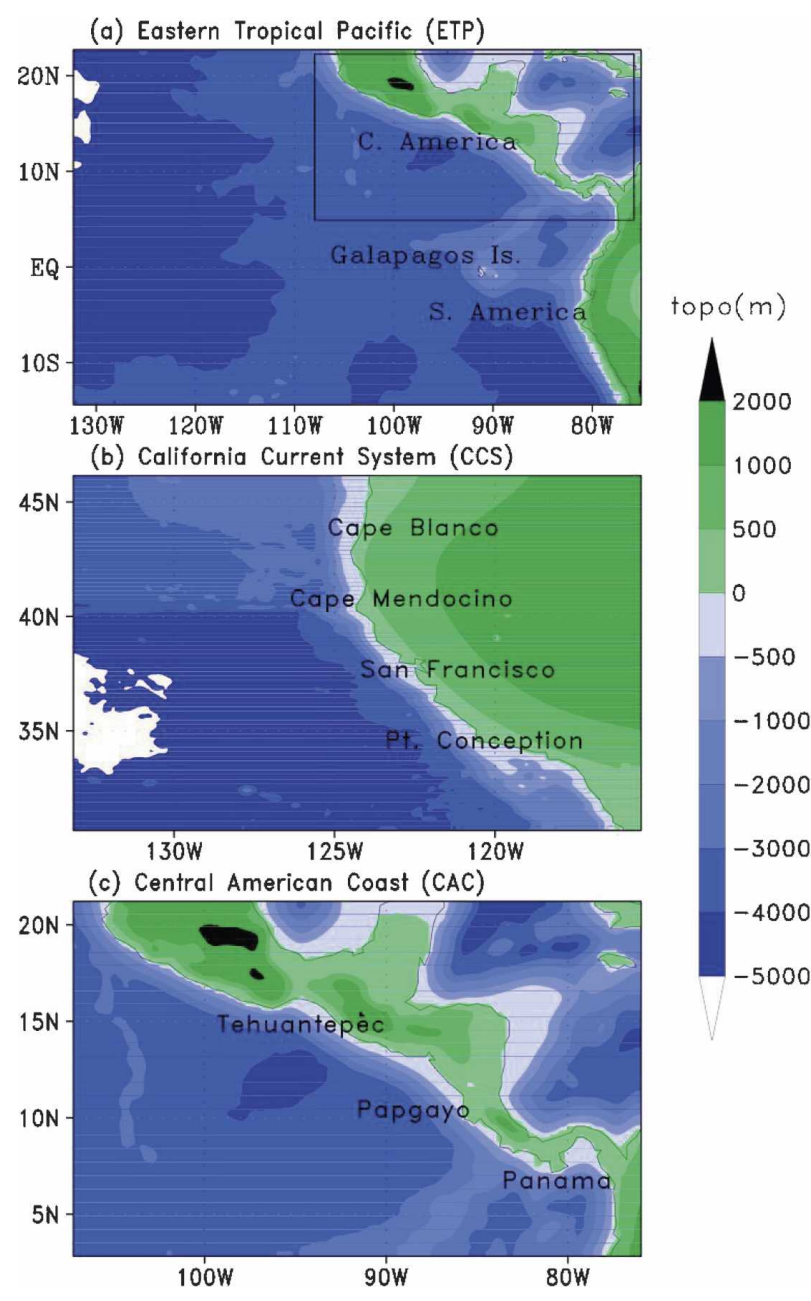

FIG. 2. Model domain, bathymetry, and orography (m) for the (a) eastern tropical Pacific (ETP), (b) California Current System (CCS), and (c) Central American coast (CAC). Solid box in (a) represents the CAC domain in (c).

case, the ocean model was first spun up using climatological atmospheric forcing for approximately eight years, followed by one to two years of coupled model spinup with realistic forcing that precede the experiments described next.

\section{a. TIWs in the ETP}

\section{1) BACKGROUND}

In the eastern tropical Pacific, SST fronts associated with the permanent cold tongue are perturbed by TIWs (Fig. 3c). They are most clearly observed from satellite measurements as wavelike oscillations of SST (Legeckis 1977; Legeckis et al. 1983; Wentz et al. 2000). These SST undulations in the Pacific are observed to have horizontal wavelengths of 1000-2000 km and periods of 20-30 days, propagating westward at $\sim 0.5 \mathrm{~m} \mathrm{~s}^{-1}$ (Qiao 
(a) Model SST and surface current

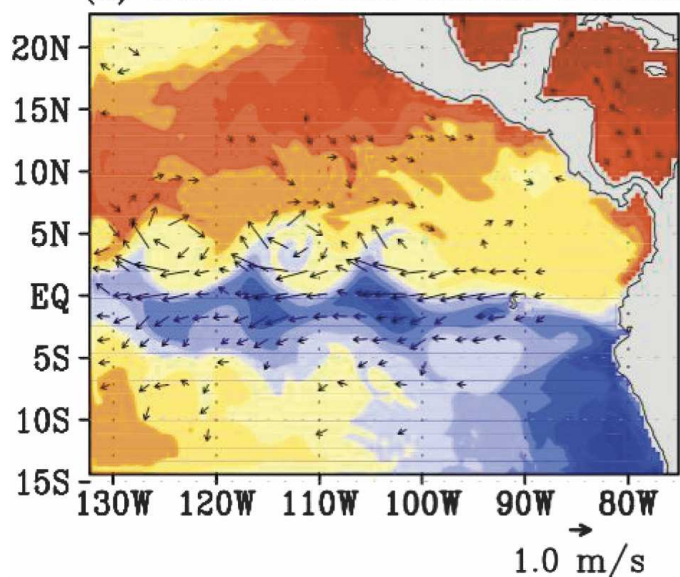

(c) Observed SST

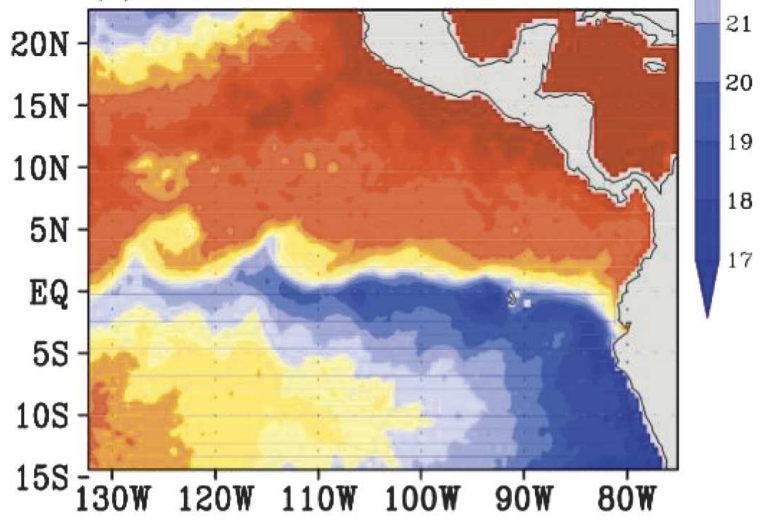

(b) Model wind stress

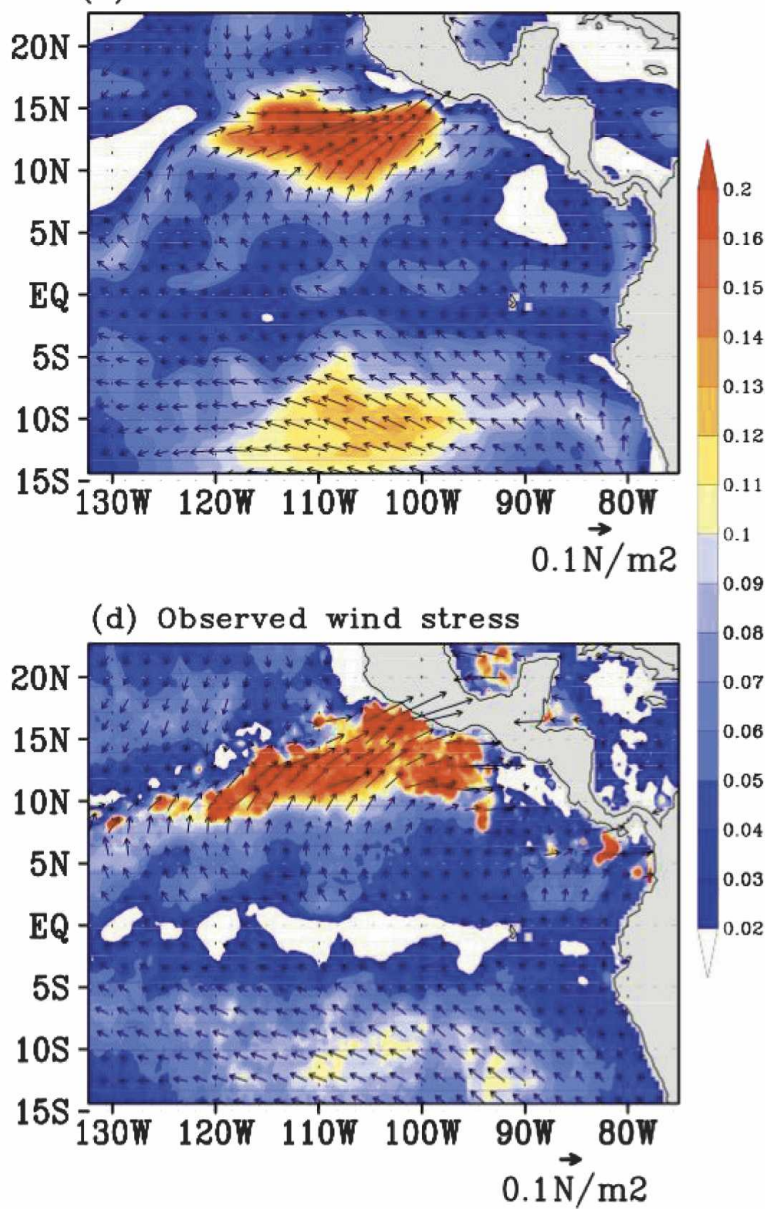

FIG. 3. Three-day-averaged oceanic and atmospheric states centered on 3 September 1999 from (a), (b) the model simulations, and (c), (d) from the observations. (a) SST $\left({ }^{\circ} \mathrm{C}\right)$ and ocean surface currents $\left(\mathrm{m} \mathrm{s}^{-1}\right)$, (b) wind stress (WS) vector and magnitude $\left(\mathrm{N} \mathrm{m}^{-2}\right)$, (c) SST $\left({ }^{\circ} \mathrm{C}\right)$ from TMI, and (d) wind stress vectors and magnitude from the QuikSCAT. Surface current speed less than $0.4 \mathrm{~m} \mathrm{~s}^{-1}$ is not plotted in (a). Wind stress magnitude less than $0.02 \mathrm{~N} \mathrm{~m}^{-2}$ is not plotted in (b) and (d).

and Weisberg 1998). Observations and numerical studies have shown that TIWs are generated by instability of the various components of the equatorial current/ countercurrent system (e.g., Philander 1976, 1978; Cox 1980; Hansen and Paul 1984; Yu et al. 1995). They are an important element in the heat budget of the equatorial cold tongue through eddy heat transport and atmospheric heat flux (Hansen and Paul 1984; Baturin and Niiler 1997; Jochum and Murtugudde 2006).

Recent studies using high-resolution satellite data highlight the vigorous air-sea coupling processes associated with the undulating SSTs generated by TIWs. Deser et al. (1993) noted the excellent correlation between SST and stratocumulus cloudiness, suggestive of SST modulation of the atmospheric boundary layer (ABL) moisture content. Hashizume et al. (2002) showed that SST-induced wind changes in the ABL are due to stability changes, as hypothesized earlier by
Sweet et al. (1981), Wallace et al. (1989), and Hayes et al. (1989). Chelton et al. (2001) argued that TIWs further affect the wind stress curl and divergence depending on the alignment of the direction of wind stress and SST gradient. The goal of the next section is to describe how the SCOAR Model captures TIW behavior and reproduces the observed response of the atmosphere to the undulating SST.

\section{2) Results}

As an initial test of the coupled model, a simulation was executed in the ETP domain for five years from 1999 to 2003 with RA2 forcing. Figure 3 illustrates the large-scale characteristics of the wind stress and its relationship to the SST fields during a typical TIW season simulated from the model and the observations. The simulated SST and wind stress are strikingly comparable with the observations, exhibiting a pronounced 


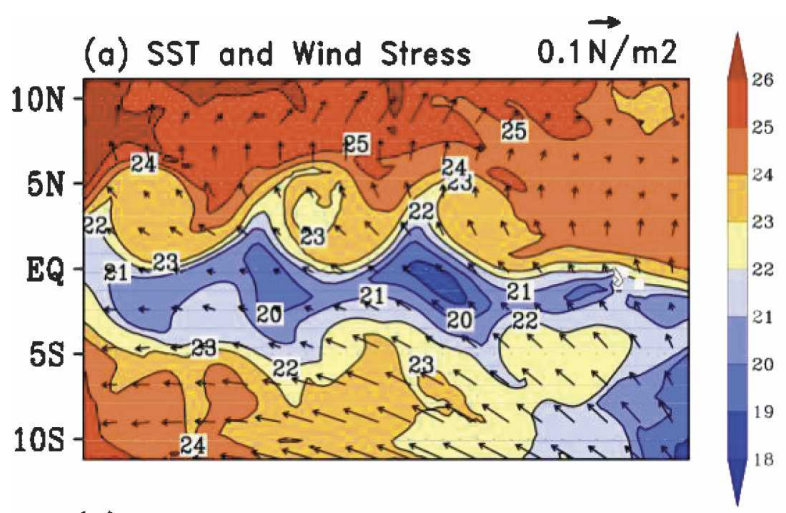

(b) Wind Stress Divergence and SST

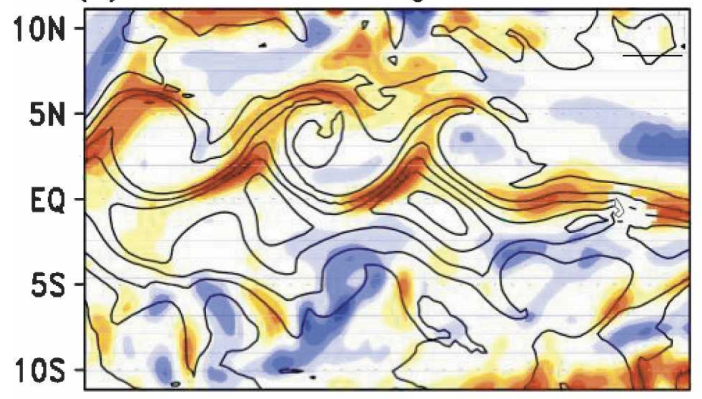

(c) Wind Stress Curl and SST

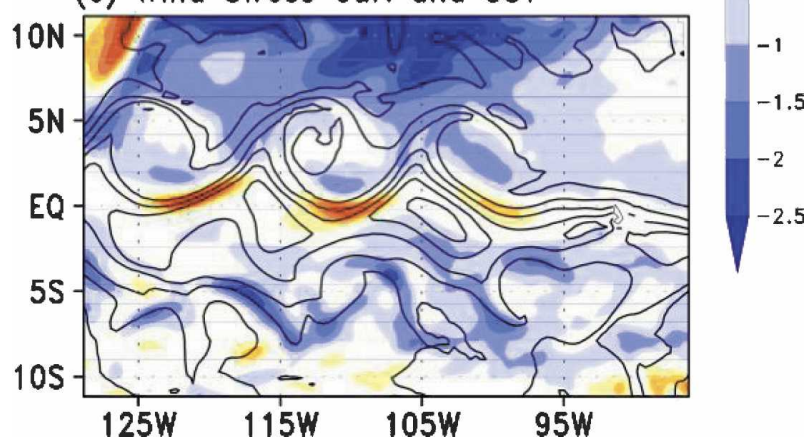

FIG. 4. Example of the SST and wind stress spatial relationship simulated by the coupled model (3-day mean centered on 5 September 1999): (a) SST $\left({ }^{\circ} \mathrm{C}\right)$ and wind stress vector $\left(\mathrm{N} \mathrm{m}^{-2}\right)$, (b) wind stress divergence $\left[\mathrm{N} \mathrm{m}^{-2}\left(10^{4} \mathrm{~km}\right)^{-1}\right]$ and SST contours shown in (a), and (c) wind stress curl $\left[\mathrm{N} \mathrm{m}^{-2}\left(10^{4} \mathrm{~km}\right)^{-1}\right]$ and SST contours shown in (a).

equatorial cold tongue and SST fronts, cusp-shaped SST fluctuations due to TIWs, and associated anticyclonic oceanic eddies. The wind stress magnitudes increase by a factor of 2 or 3 over the regions east of the cold cusps. Discrepancies in the details between modeled and observed TIWs are due to them being a result of an internal instability of the ocean rather than being deterministically forced.

The undulating SST patterns are associated with perturbations of the wind stress field (Figs. 3b, 4a). The wind stress perturbations occur in phase with SST, with stronger (weaker) wind stress over warm (cold) SST. The effect of SST on the wind stress derivatives, however, depends on the alignment of the direction of wind stress and SST gradient vector (Chelton et al. 2001). Figures $4 \mathrm{a}, \mathrm{b}$ show that, when the winds blow parallel to the SST gradient vectors (perpendicular to the isotherms), the positive maximum divergence occurs where the SST gradients are steepest. On the other hand, Figs. 4a,c show pronounced positive wind stress curl closely following the SST waves where winds blow parallel to the isotherms. Kessler et al. (2003) found that inclusion of the these narrow strips of positive wind stress curl in the forcing of the Sverdrup flow substantially improved its match to the observed zonal current system. This suggests the importance of local air-sea interactions on the regional ocean circulation. It is encouraging that the SCOAR Model produces perturbation wind stress curl patterns quantitatively comparable to those of QuikSCAT via local air-sea interactions (cf. our Fig. 4c with Fig. 4e in Chelton et al. 2001).

The coupling of wind and SST displays a coherent spatial and temporal variability. Figures 5 and 6 show time-longitude diagrams of SST and wind stress north $\left(1^{\circ} \mathrm{N}\right)$ and south $\left(4^{\circ} \mathrm{S}\right)$ of the cold tongue during the cold season (June-December) of 1999. SST propagates westward in time both north and south of the cold tongue. The phase speed of SST north of the cold tongue is approximately $0.6 \mathrm{~m} \mathrm{~s}^{-1}$, with maximum SST anomaly exceeding $2^{\circ} \mathrm{C}$. It should also be noted that the model visibly reproduces the Southern Hemisphere signature of the TIWs, which is an underappreciated characteristic of TIWs (Chelton et al. 2000c; Hashizume et al. 2001) perhaps due to limited data coverage of the observations in the Tropics. Consistent with Chelton et al. (2000c, 2001), the TIWs in the south are less well defined and exhibit faster propagations compared to the north. Figures 5a and 6a show nearly in-phase propagation between SST and wind stress magnitude, again indicating the tight coupling between SST and the resultant surface wind stress.

The TIW-induced SST anomalies clearly perturb the divergence and curl of the wind stress fields in the atmosphere. Figures $5 \mathrm{c}$ and $6 \mathrm{c}$ (Figs. $5 \mathrm{~d}$ and $6 \mathrm{~d}$ ) show the relation between the perturbation wind stress divergence (curl) and downwind (crosswind) SST gradient, similar to the figures from Chelton et al. (2001). Downwind and crosswind SST gradients are computed respectively from $\boldsymbol{\nabla} T \cdot \hat{\tau}=|\boldsymbol{\nabla} T| \cos \theta$ and $\boldsymbol{\nabla} T \times \hat{\tau} \cdot \mathbf{k}=$ $|\nabla T| \sin \theta$, where $T$ is SST, $\hat{\tau}$ is a unit vector in the direction of the wind stress, and $\theta$ is the counterclockwise angle from the vector $\boldsymbol{\nabla} T$ to $\hat{\tau}$. Model-simulated relations between the perturbation wind stress divergence (curl) and downwind (crosswind) SST gradient 
(a) WS \& SST at $1 \mathrm{~N}$

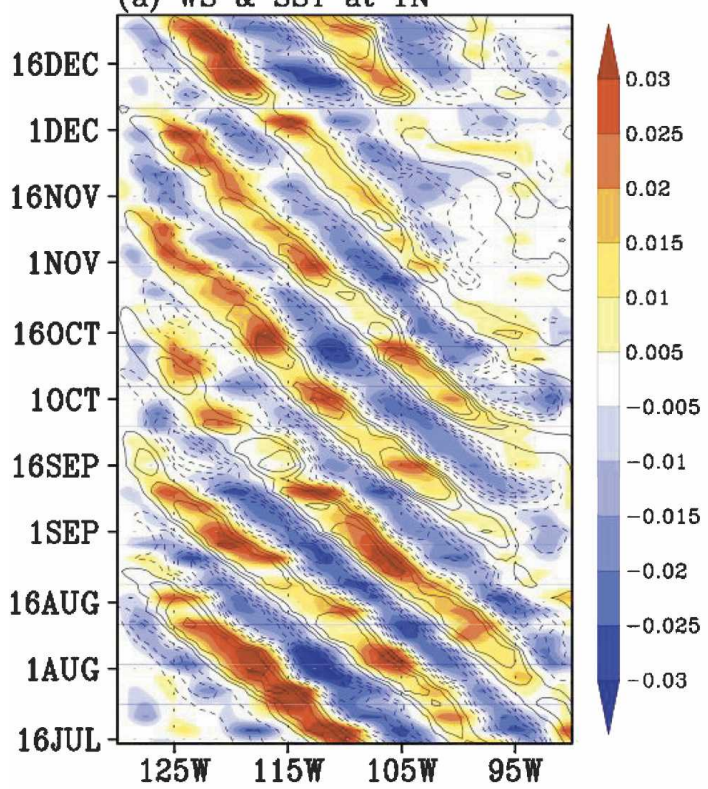

(c) WSD \& ddT
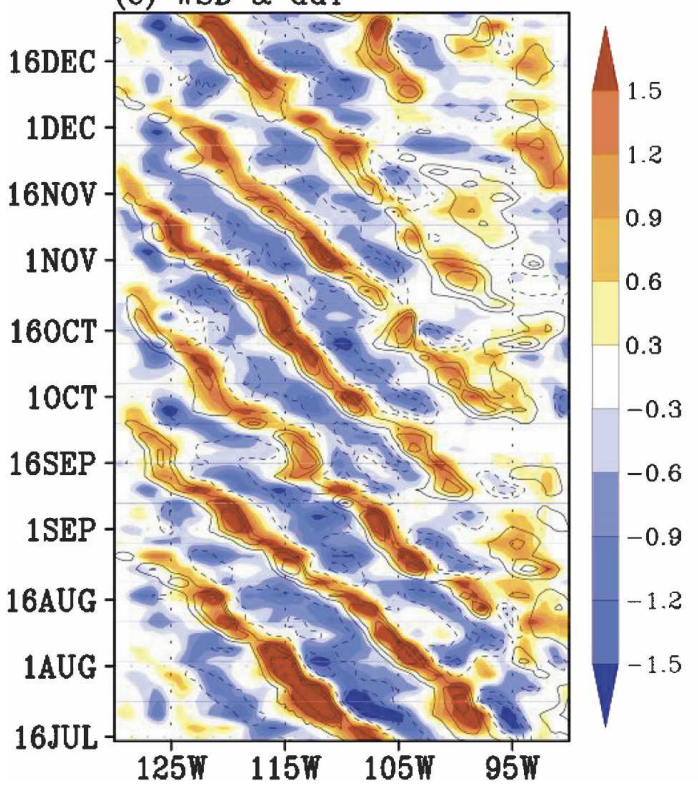

(b) LH \& SST

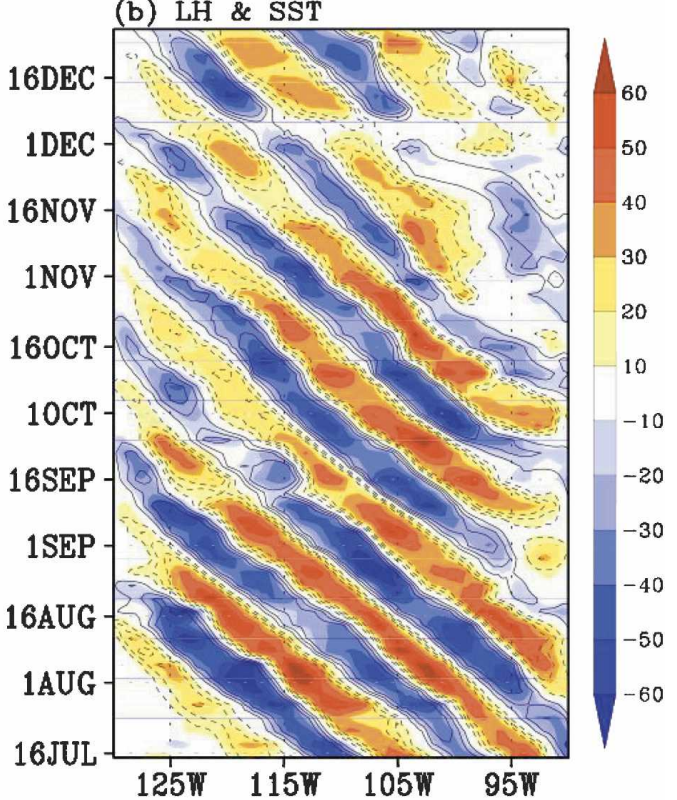

(d) WSC \& cdT

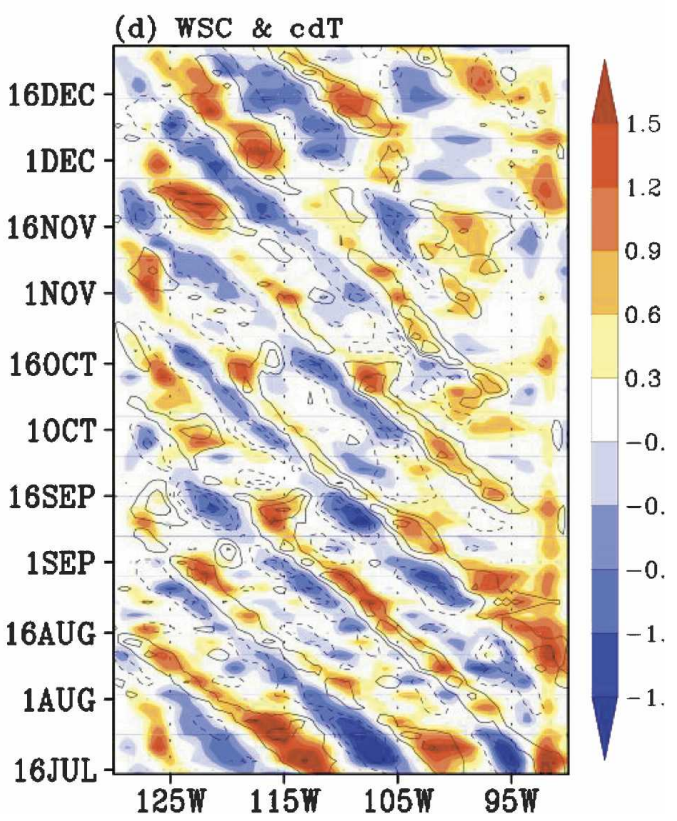

FIG. 5. Longitude-time plots along $1^{\circ} \mathrm{N}$ on the north side of the equator of model SST and wind stress fields from $16 \mathrm{Jul}$ to 31 Dec 1999: (a) perturbation wind stress (WS) with contours of perturbation SST $\left({ }^{\circ} \mathrm{C}\right)$, (b) perturbation latent heat flux $\left(\mathrm{N} \mathrm{m}^{-2}\right)$ with contours of perturbation SST $\left({ }^{\circ} \mathrm{C}\right)$, (c) wind stress divergence (WSD) $\left[\mathrm{N} \mathrm{m}^{-2}\left(10^{4}\right.\right.$ $\mathrm{km})^{-1}$ ] overlaid with contours of downwind SST gradient (ddT) $\left[{ }^{\circ} \mathrm{C}(100 \mathrm{~km})^{-1}\right.$ ], and (d) wind stress curl (WSC) $\left[\mathrm{N} \mathrm{m}^{-2}\left(10^{4} \mathrm{~km}\right)^{-1}\right]$ overlaid with contours of crosswind SST gradient $(\mathrm{cdT})\left[{ }^{\circ} \mathrm{C}(100 \mathrm{~km})^{-1}\right]$. Contour intervals for SST in (a) and (b) are $0.5^{\circ} \mathrm{C}$, and contour intervals for ddT in (c) and cdT in (d) are $0.5^{\circ} \mathrm{C}(100 \mathrm{~km})^{-1}$. For clarity, contours of zero values are not plotted. Solid (dashed) contours represent positive (negative) values.

appear to be generally consistent with the observations, with positive divergence (curl) copropagating with positive downwind (crosswind) SST gradient in Figs. 5c, 6c (Figs. 5d, 6d).

The simple positive correlations between SST gradi- ent and the perturbed wind stress derivatives are illustrated more precisely with binned scatterplots in Fig. 7. Coupling coefficients estimated from the linear fit between the perturbed wind stress divergence (curl) and downwind (crosswind) SST gradient in the model are 
(a) WS \& SST at $4 \mathrm{~S}$

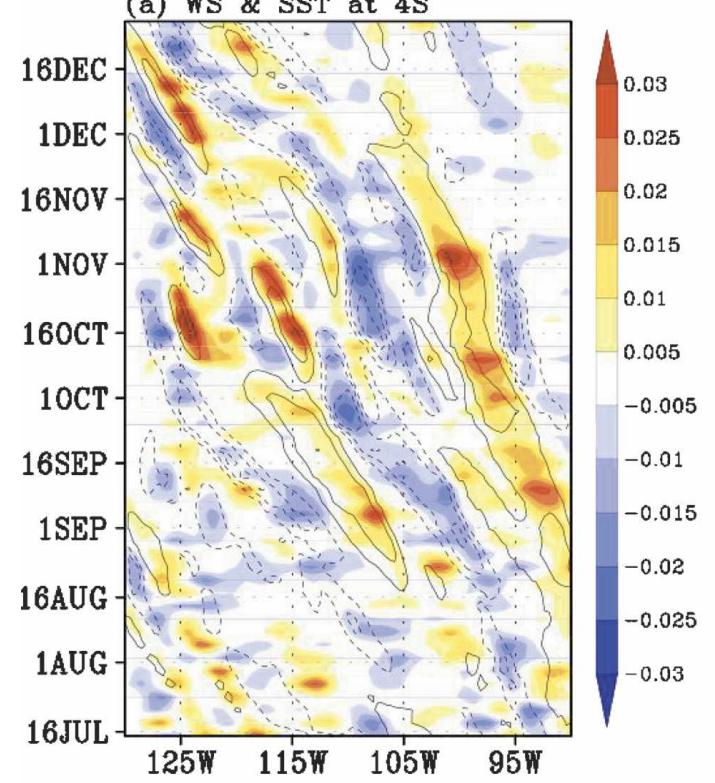

(c) WSD \& ddT

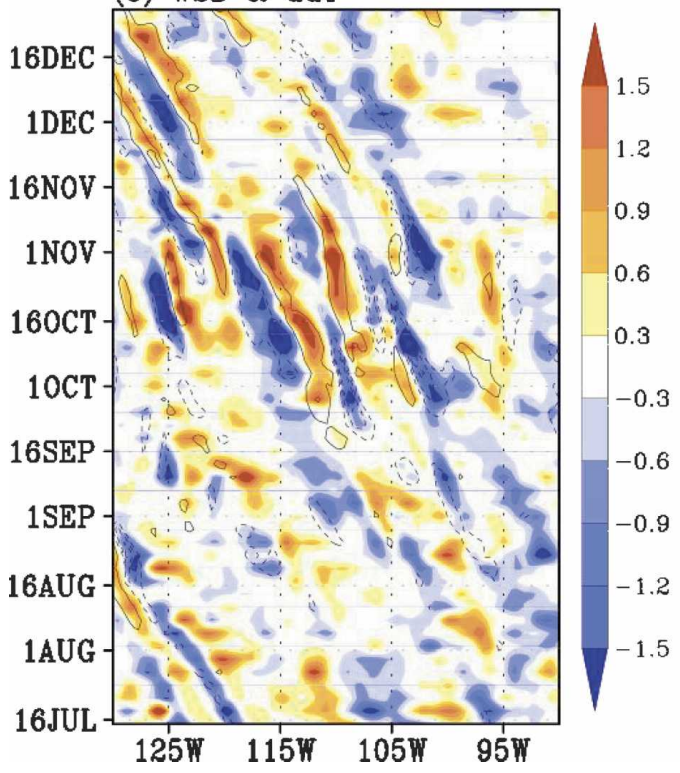

(b) LH \& SST

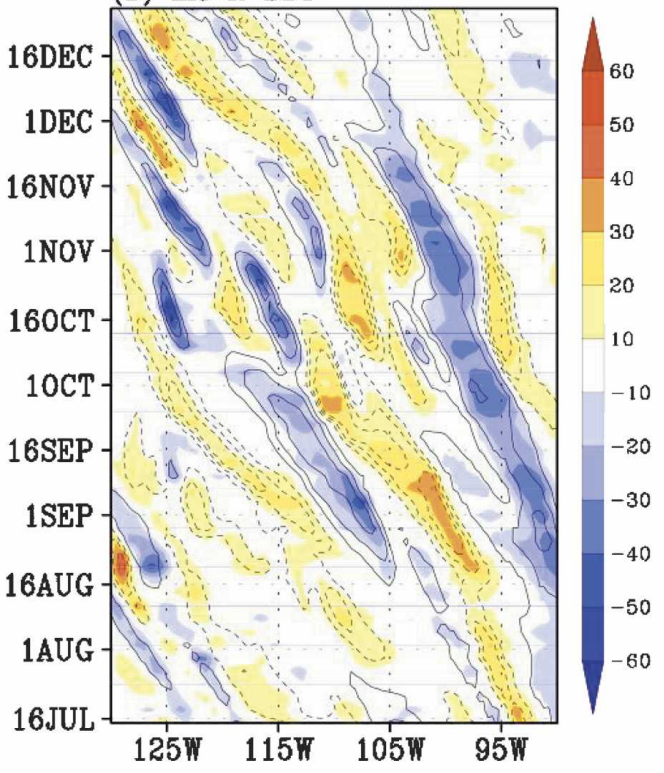

(d) WSC \& cdT

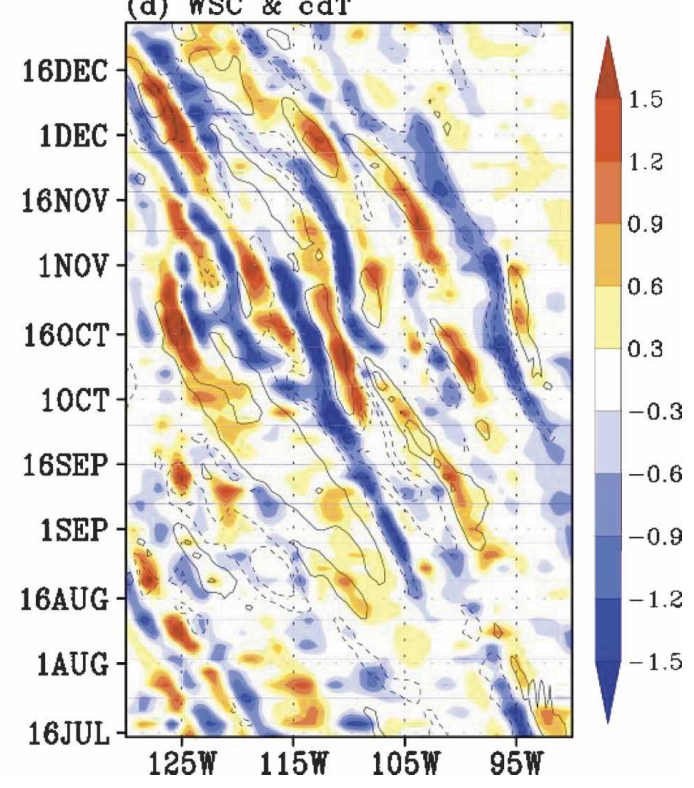

Fig. 6. As in Fig. 5 except along $4^{\circ} \mathrm{S}$ on the south side of equator.

1.5 (0.9), comparable to the values computed from observations by Chelton (2005) over a similar region.

Consistent with the previous observations, the wind stress curl response to the SST gradient is smaller than that of the divergence. Chelton et al. (2001) suggest that the weaker response in wind stress curl can be explained by ocean surface currents that are in the direction of wind stress near the region of maximum crosswind SST gradient. Surface currents in this region reach nearly $1 \mathrm{~m} \mathrm{~s}^{-1}$ (Fig. 3a) and are in the same direction as near-surface winds $\left(\sim 4 \mathrm{~m} \mathrm{~s}^{-1}\right.$, not shown).
We performed a simple sensitivity test to examine the contribution of ocean surface currents to the wind stress fields. Identical atmospheric forcing during the cold season (July to December) of the year of 1999 from SCOAR was prescribed in two forced ROMS runs, with the ocean current effect on stress included in one but not in the other. This sensitivity test revealed that the strength of coupling of wind stress curl to crosswind SST gradient is reduced by roughly $25 \%$ when the ocean current effect is allowed, while coupling of divergence to downwind SST gradient remains nearly con- 
(a) WSD and ddT

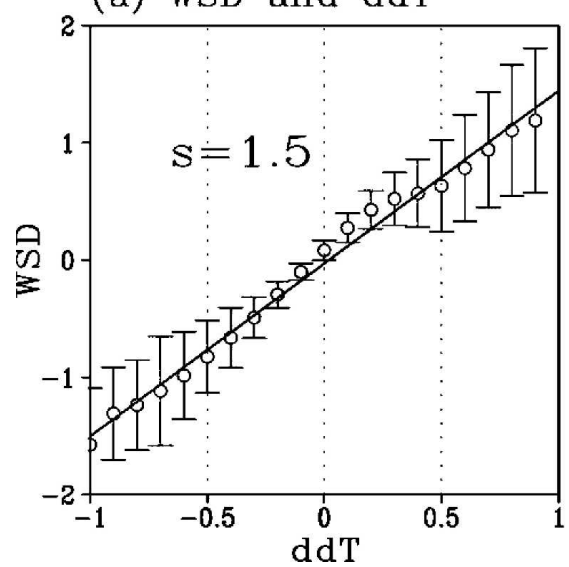

(b) WSC and cdT

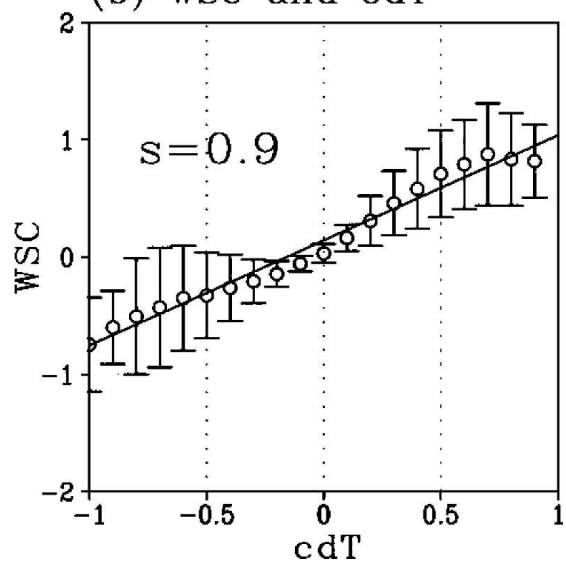

FIG. 7. Binned scatterplots of (left) the zonally high-pass-filtered wind stress divergence (WSD) $\left[\mathrm{N} \mathrm{m}^{-2}\left(10^{4} \mathrm{~km}^{-1}\right]\right.$ and the downwind SST gradient $(\mathrm{ddT})\left[{ }^{\circ} \mathrm{C}(100 \mathrm{~km})^{-1}\right]$, and (right) wind stress curl (WSC) $\left[\mathrm{N} \mathrm{m}^{-2}\left(10^{4} \mathrm{~km}\right)^{-1}\right]$ and crosswind SST gradient $(\mathrm{cdT})\left[{ }^{\circ} \mathrm{C}(100\right.$ $\mathrm{km})^{-1}$ ] over $5^{\circ} \mathrm{S}-5^{\circ} \mathrm{N}, 125^{\circ}-100^{\circ} \mathrm{W}$ from cold seasons (July to December) for $5 \mathrm{yr}$ (19992003). Solid circles in the plot indicate the overall mean values within each bin for the whole period of time, and the error bars represent the \pm 1 standard deviations of the scatter. The solid lines through the binned means represent least squares fits of the binned means to the straight lines. The parameter, $s$, in each plot indicates the slopes of the fitted line (coupling strength). Daily SST at $42-\mathrm{km}$ ROMS grid was smoothed using $2^{\circ}$ latitude by $4^{\circ}$ longitude block running mean. The SST gradient was computed from the resultant smoothed SST by centered differences. The wind stress curl and divergence (and heat flux) were computed from the unsmoothed wind stress at 50-km RSM grid by the same difference method. Then, the derivative SST and wind stress fields were zonally high-pass filtered to reduce the variability with zonal scales longer than $20^{\circ}$ longitudes. The binned scatters were computed based on 3-day-averaged data of the resultant high-pass-filtered fields.

stant (not shown). This reduction accounts for a large part of the $40 \%$ weaker response in curl than in divergence seen in Fig. 7. The remaining difference may be attributable to the different adjustment time scales for atmospheric flow along or across an SST front, as discussed in Chelton et al. (2001).

Latent and sensible heat fluxes associated with the TIWs are affected both by SST directly, by altering the stability of the ABL, and indirectly, by the influence of SST on the wind speed variations (Thum et al. 2002). Since wind stress and SST are in phase, the latent heat flux and SST are out of phase (Figs. 5, 6b and Fig. 8a). Increased winds over the warm water on the eastern sides of the cold cusps enhance the evaporative cooling at the sea surface, and thus decrease SST. Sensible heat flux is also out of phase with SST, resulting in sensible cooling of warm water with a smaller magnitude than latent heat flux (Fig. 8c).

The qualitative description of the relation between SST and surface turbulent heat flux is in agreement with the previous study by Zhang and McPhaden (1995). They found that, on TIWs-related time scales in the eastern Pacific cold tongue, SST variations are important in forcing latent heat flux variations, implicat- ing an instantaneous atmospheric response to SST. The simulated latent heat flux anomaly from the SCOAR Model is about $34 \mathrm{~W} \mathrm{~m}^{-2}\left[1^{\circ} \mathrm{K} \mathrm{SST}^{-1}\right.$ based linearfitted line of binned scatters (Fig. 8b), somewhat lower than the observed estimates of $40 \mathrm{~W} \mathrm{~m}^{-2}$ by Thum et al. (2002) and $50 \mathrm{~W} \mathrm{~m}^{-2}\left[1^{\circ} \mathrm{K} \mathrm{SST}^{-1}\right.$ by Zhang and McPhaden (1995). According to the simple calculation by Thum et al. (2002), this anomaly in latent heat flux would produce $0.5^{\circ} \mathrm{C}$ cooling of warm water, unambiguously indicating a negative feedback on the SST. Furthermore, Deser et al. (1993) found the increased lowlevel cloudiness over warm SST on TIW scales, hence reducing solar insolation reaching the sea surface. The resultant impact is to cool warm water at roughly $0.6^{\circ} \mathrm{C}$ (month $)^{-1}$, again indicating a negative feedback. Therefore the surface heat flux response to the evolving SST would be to suppress the development of SST anomalies by TIWs (a negative feedback), as discussed by numerous investigators (e.g., Liu et al. 2000; Chelton et al. 2001; Thum et al. 2002; Xie 2004).

The vertical stratification of the upper ocean and lower atmosphere associated with TIWs is presented in Figs. 9a,c for a longitudinal transect of the model. In the upper ocean, sharp patches of cold water periodically 
(a) Latent heat flux SST

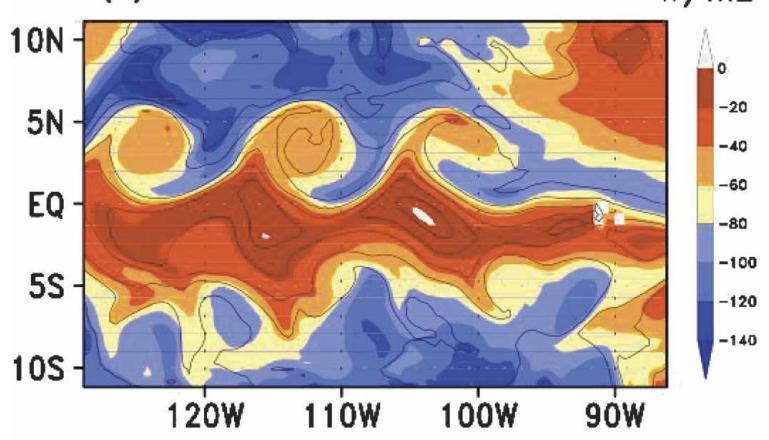

(c) Sensible heat flux and SST

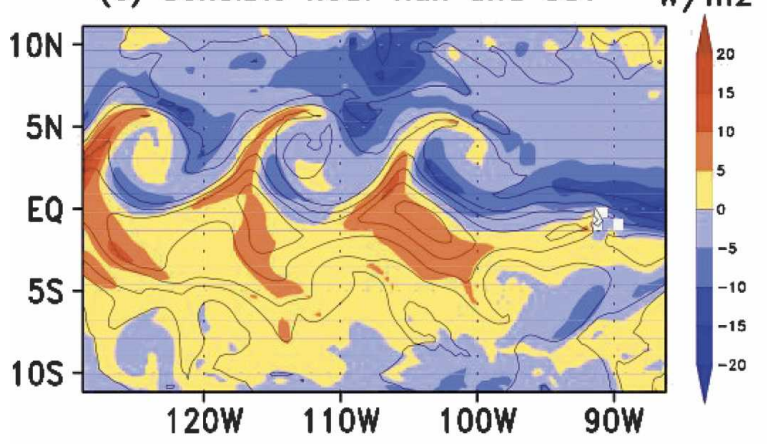

(b) Latent heat flux and SST

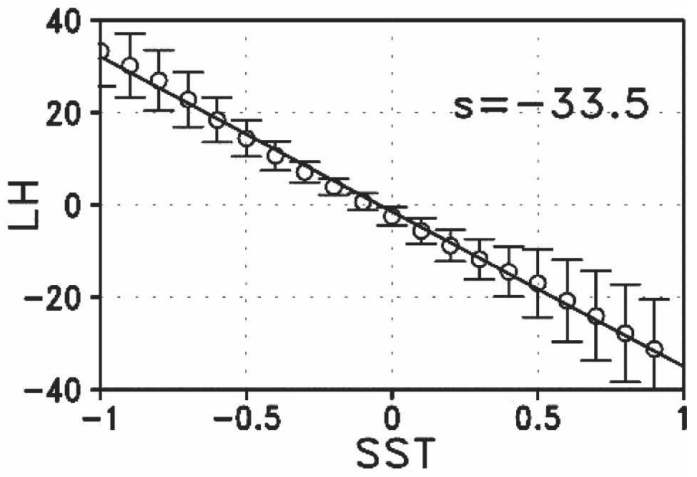

(d) Sensible heat flux and SST

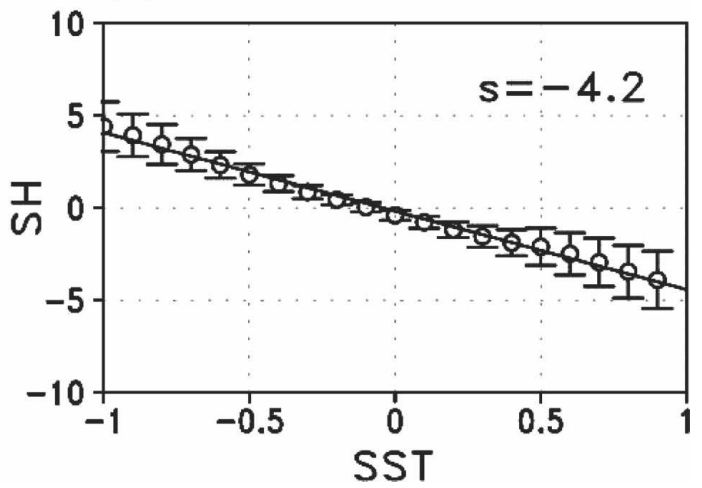

FIG. 8. (a), (c) As in Fig. 4 except (a) latent heat flux $\left(\mathrm{W} \mathrm{m}^{-2}\right)$ overlaid with contours of SST $\left({ }^{\circ} \mathrm{C}\right)$ shown in Fig. $4 \mathrm{a}$, (c) sensible heat flux $\left(\mathrm{W} \mathrm{m}^{-2}\right)$ with contours of SST $\left({ }^{\circ} \mathrm{C}\right)$ shown in Fig. 4a. (b), (d) Same as in Fig. 7, except for plots of (b) perturbation latent heat flux $\left(\mathrm{W} \mathrm{m}^{-2}\right)$ and SST $\left({ }^{\circ} \mathrm{C}\right)$ and $(\mathrm{d})$ perturbation sensible heat flux $\left(\mathrm{W} \mathrm{m}^{-2}\right)$ and SST $\left({ }^{\circ} \mathrm{C}\right)$. The convention of sign of heat flux is such that positive flux warms the ocean. SST and latent and sensible heat flux used in the binned scatterplots were low-pass and high-pass filtered as described in Fig. 7.

reach the surface roughly every $11^{\circ}$ longitude. The alternating occurrence of cold and warm water implies anticyclonic ocean eddies, as seen in the map of SST in Fig. 3a as vectors of surface current. The simulation also reveals the enhanced stratification of the upper ocean below the eastern part of the anticyclonic eddies as indicated by the steeper thermocline (Fig. 9d).

In the atmosphere, waves of temperature with similar wavelengths as TIWs are found below the model mixed layer $(\sim 400 \mathrm{~m})$, suggesting that SST affects the vertical stratification of the lower atmosphere. Over cold waters stratification is markedly enhanced, decoupling the surface mixed layer from the flow aloft. This reduces the turbulent mixing of momentum (Wallace et al. 1989), thus decreasing winds near the surface and increasing winds aloft (Fig. 9b). In particular, the increase of winds aloft (above $400 \mathrm{~m}$ ) over cold water has been barely evident in the observations, perhaps due to the superimposed synoptic variability (e.g., Hashizume et al. 2002). More comprehensive fieldwork during the East Pacific Investigation of Climate (EPIC) 2001 (Cro- nin et al. 2002; Raymond et al. 2004) showed the stronger zonal and meridional winds over cold water at heights between 400 and $800 \mathrm{~m}$ (de Szoeke et al. 2005; Small et al. 2005). The model studies by de Szoeke and Bretherton (2004) and Small et al. (2003, 2005) also produced similar results. Another important point here is whether SST influences the atmosphere above the atmospheric model boundary layer. If it does, then it would suggest that SST might be more important than previously believed on these spatial and temporal scales in climate modeling (Seo et al. 2006).

\section{b. Mesoscale eddy feedbacks in the CCS}

\section{1) BACKGROUND}

The tight associations between SST and the ABL on the ocean mesoscale are not limited to the tropical ocean but are commonly observed in the subtropics and midlatitude ocean (e.g., Behringer et al. 1979; Nonaka and Xie 2003; Vecchi et al. 2004; O'Neill et al. 2005). As one example, consider the rich mesoscale features of 
(a) Atmospheric temperature

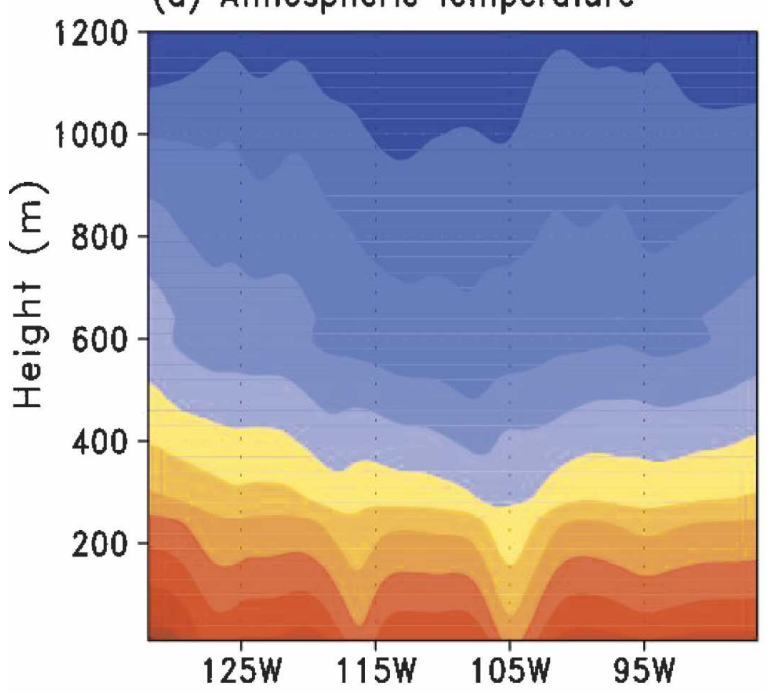

(c) Ocean temperature

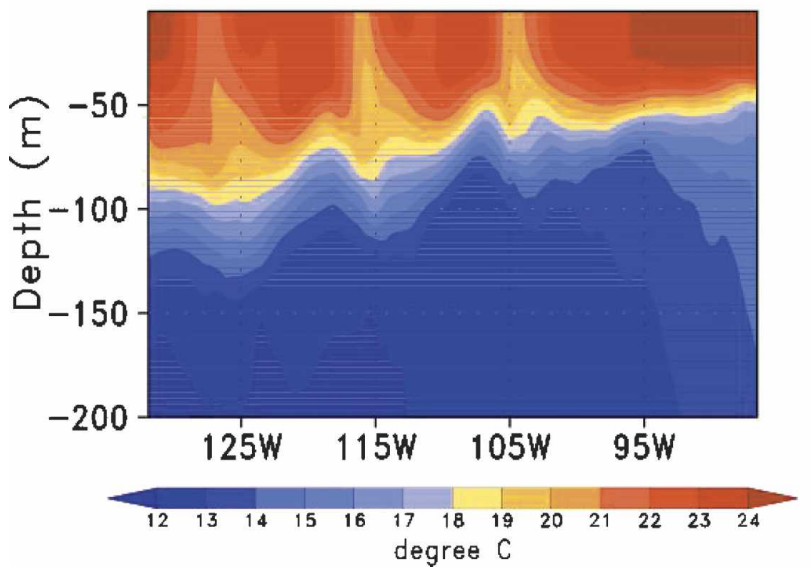

(b) Zonal wind profile

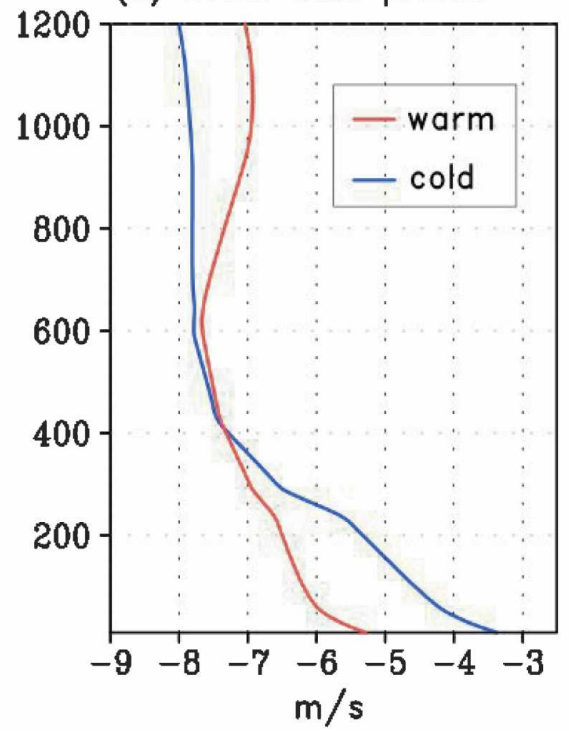

(d) Ocean temperature profile

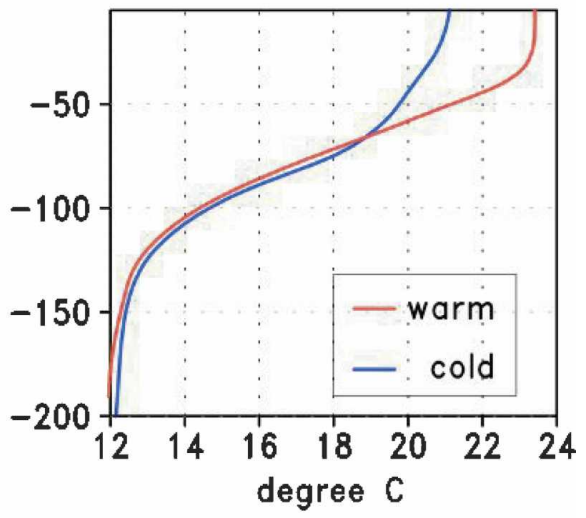

FIG. 9. (a), (c) Longitude-height (depth) cross sections of (a) atmospheric temperature $\left({ }^{\circ} \mathrm{C}\right)$ and (c) ocean temperature $\left({ }^{\circ} \mathrm{C}\right)$ from 2 to 4 Sep 1999 averaged from $1^{\circ}$ to $2^{\circ} \mathrm{N}$. (b), (d) The composite profiles of (b) zonal wind $\left(\mathrm{m} \mathrm{s}^{-1}\right)$ and (d) vertical ocean temperature $\left({ }^{\circ} \mathrm{C}\right)$. Red (blue) lines are mean profiles when zonal deviation of SST is warmer (colder) than one standard deviation. There were 17 (15) warm (cold) phases from 2 to 4 Sep 1999.

the California Current System (Hickey 1979), which is characterized by seasonal development of equatorward alongshore winds and corresponding coastal upwelling (Allen 1980; Lynn and Simpson 1987). Associated with this coastal upwelling are thin, cold filaments and squirts that extend far offshore (Strub and James 2000).

Chelton et al. (2007) showed that ocean-atmosphere coupling is observed in the CCS region during the summertime where the upwelling fronts are well developed. Based on the analysis of QuikSCAT wind stress along with the newly available SST dataset from the advanced Microwave Scanning Radiometer on the Earth Observ- ing System (EOS) Aqua satellite (AMSR-E) on monthly times scales, they concluded that SST fronts generated by mesoscale variability and coastal upwelling exert an unambiguous influence on the perturbation of summertime wind stress curl (and divergence). The dynamical effects on the CCS may be far more important than in the equatorial ocean. Haack et al. (2005) also found that positive wind stress curls were closely aligned with the tight SST gradient prescribed in their COAMPS atmospheric model, implicating an important dynamic feedback to ocean. Chelton et al. (2007) suggest that open ocean Ekman pumping due to this SST-generated wind stress curl is as important as 
Ekman transport due to alongshore wind forcing in the CCS region (see also Pickett and Paduan 2003).

The observed strong coupling and dynamic feedback strongly suggest that this ocean-to-atmosphere forcing may be substantially underestimated in conventional forced ocean and atmospheric CCS models. Current coastal weather forecast models neglect the mesoscale ocean-to-atmosphere forcing and the subsequent feedbacks. Eddy-resolving regional ocean models forced with the observed high-resolution wind stress will also suffer from consistency problems unless the ocean model reproduces SST fields that quantitatively match observations. Numerical studies with high-resolution ocean-atmosphere coupling will be essential to provide new insights to the dynamics of the CCS region. The goal of the next section is to describe how the SCOAR Model captures CCS behavior and reproduces the observed response of the atmosphere to midlatitude mesoscale eddies.

\section{2) Results}

As an initial test of the coupled model in the CCS region, a simulation was executed for 4 years from 2001 to 2004 with RA2 forcing. The results are analyzed based on monthly mean data to facilitate comparison with the observational estimates by Chelton et al. (2007). It should be noted, however, that the coupling coefficient (defined as the linear relationship between the derivative wind stress fields and the SST gradient) is somewhat sensitive to the subjectively chosen temporal and spatial averaging scales.

Figure 10 shows typical summertime statistics of SST and wind stress fields obtained from the model in July 2003. Equatorward wind stress is predominant during the summertime along the coast (Fig. 10a). Two wind stress maxima $\left(>0.14 \mathrm{~N} \mathrm{~m}^{-2}\right)$ are found off Cape Mendocino and Pt. Conception. In association with these wind patterns, the SST distribution is zonally asymmetric, with colder upwelled SSTs near the coast and warmer SST offshore. Figure 10b shows that both coastal upwelling filaments and offshore mesoscale eddies generate SST gradients greater than $\sim 5^{\circ}-6^{\circ} \mathrm{C}$ over $100 \mathrm{~km}$, in agreement with that inferred from satellites (Chelton et al. 2007; Castelao et al. 2006). The resultant SST fronts reveal a similar impact on the monthly mean wind stress derivatives and surface heat fluxes as found for TIWs. The alignment of the SST gradient vectors to the overlying wind stress directions causes spatially coherent patterns between wind stress divergence and downwind SST gradient (Fig. 10c) and between wind stress curl and crosswind SST gradient (Fig. 10d). It is also apparent that the gradient of latent heat flux is almost in phase with the SST gradient. On ocean eddy scales, positive SST and negative latent heat flux (and sensible heat flux, not shown) are spatially in phase, while on larger scales they are not.

The strength of the linear response of monthly mean wind stress curl (divergence) to crosswind (downwind) SST gradient was also evaluated for this region using binned scatterplots in the same region as Chelton et al. (2007; Figs. 11a-c). The coupling coefficients inferred from the linear fits between the respective derivatives are $\sim 0.5$ for wind stress divergence and downwind SST gradient, and $\sim 0.2$ for wind stress curl and crosswind SST gradient. This coupling strength is weaker by a factor of $\sim 5$ for divergence and $\sim 10$ for curl than that inferred from observations by Chelton et al. (2007), in contrast to the TIW region where the coupled model produced comparable slopes.

The reason for the smaller coupling coefficients in the model may be that spatial patterns of seasonal mean wind stress and SST are somewhat different from the observations, with the summer wind stress maximum and CCS SST front located roughly $200 \mathrm{~km}$ farther offshore than observed (not shown). The inconsistency may be partly due to the use of climatological lateral boundary conditions for the ocean. Additionally, the coupled model does not implement data assimilation in the atmospheric component as some other regional atmospheric models do (see Perlin et al. 2004), resulting in a biased mean state and different distributions for the variance fields. For example, the bottom panel of Fig. 11 shows binned scatterplots over a region that has variance levels more comparable to those in the region defined by Chelton et al. (2007) from observations. The coupling strength in this region is larger than found in the upper panel, although still much weaker than observed.

Midlatitude air-sea coupling at oceanic frontal scales in this eastern boundary current region also may not be adequately captured by this model for several other reasons. Stronger synoptic weather variability, smaller scales of SST fronts, and interactions involving the coastline and coastal orography could obscure the relevant coupling signals in this region compared to the resounding signals found in the Tropics. However, Fig. 10 and Fig. 11 clearly reveal that the SCOAR Model generates coupling signals in the CCS region qualitatively comparable to the observations, even with climatological biases.

\section{c. Gap winds in the $C A C$}

\section{1) BACKGROUND}

The high-elevation mountains of the Sierra Madres along the central American cordillera block low-level 
(a) SST and wind stress

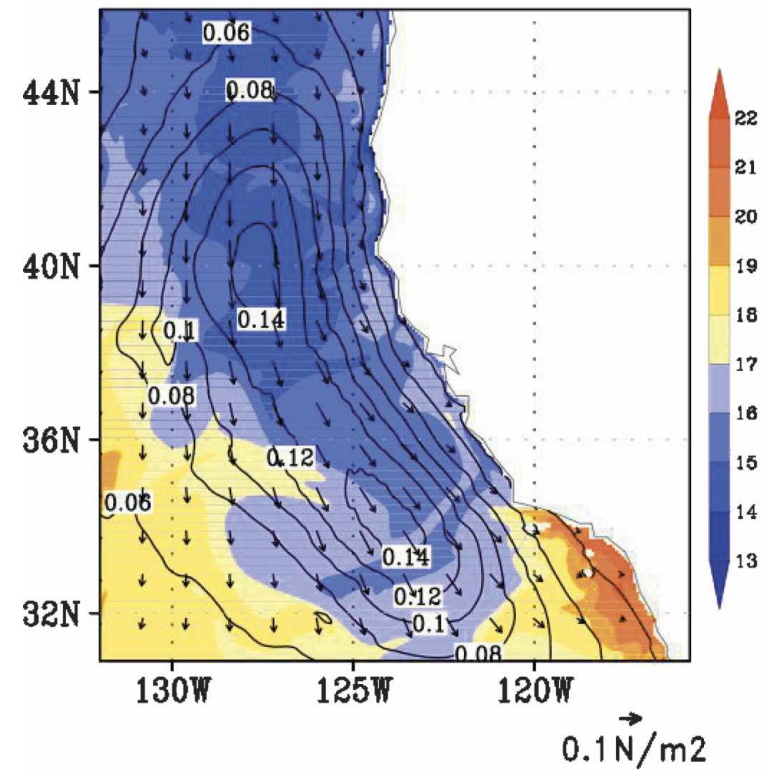

(c) WSD and ddT

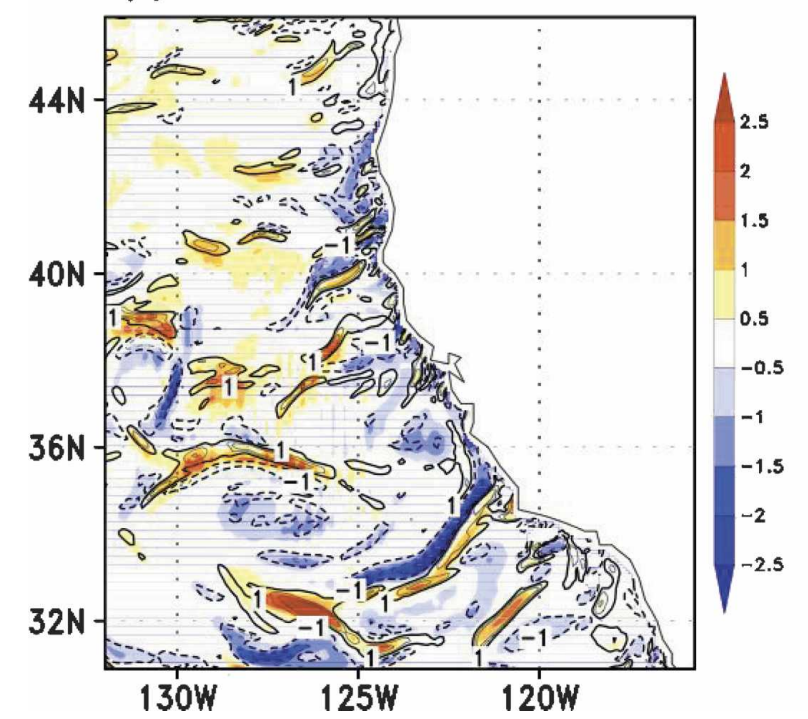

(b) $|\mathrm{dLH}|$ and $|\mathrm{dT}|$

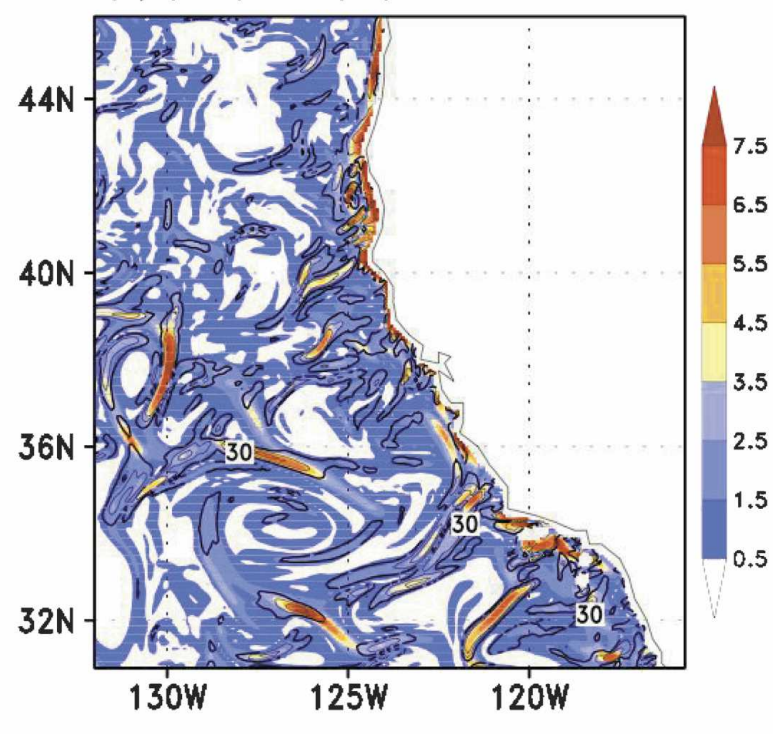

(d) WSC and cdT

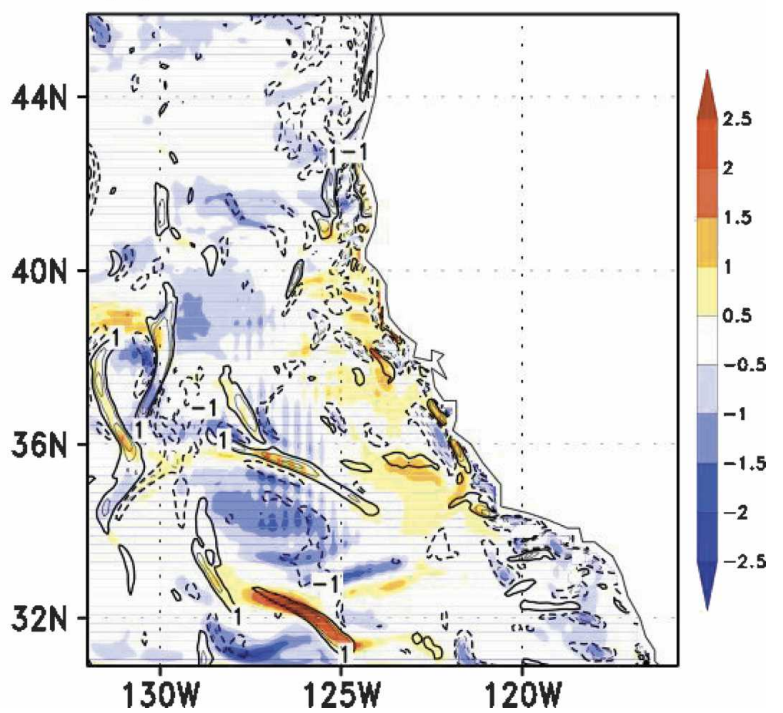

FIG. 10. Model-derived 30-day average fields of SST and wind stress in July 2003: (a) SST $\left({ }^{\circ} \mathrm{C}\right)$ overlaid with vectors of wind stress (WS) and contours of WS magnitude $\left(\mathrm{N} \mathrm{m}^{-2}\right)$, (b) absolute values of latent heat flux gradient $\left\{|d \mathrm{LH}|\left[\mathrm{W} \mathrm{m}{ }^{-2}\left(10^{4} \mathrm{~km}\right)^{-1}\right]\right\}$ with contours of SST gradient $(|d T|)\left[^{\circ} \mathrm{C}(100 \mathrm{~km})^{-1}\right]$, (c) anomalous wind stress divergence (WSD) $\left[\mathrm{N} \mathrm{m}^{-2}\left(10^{4} \mathrm{~km}\right)^{-1}\right]$ with contours of downwind SST gradient $\left[{ }^{\circ} \mathrm{C}(100 \mathrm{~km})^{-1}\right.$ ], and (d) anomalies of wind stress curl (WSC) $\left[\mathrm{N} \mathrm{m}^{-2}\left(10^{4} \mathrm{~km}\right)^{-1}\right.$ ] with contours of crosswind SST gradient $\left[{ }^{\circ} \mathrm{C}(100 \mathrm{~km})^{-1}\right]$. Contour interval of wind stress magnitudes in (a) is $0.02 \mathrm{~N} \mathrm{~m}^{-2}$. Contours of $|d \mathrm{LH}|$ are every $30 \mathrm{~W}$ m ${ }^{-2}$ $(100 \mathrm{~km})^{-1}$ [thick contours for $30 \mathrm{~W} \mathrm{~m}^{-2}(100 \mathrm{~km})^{-1}$ ]. WSC and WSD are plotted every $1 \mathrm{~N} \mathrm{~m}^{-2}\left(10^{4} \mathrm{~km}\right)^{-1}$ [thick contours for \pm 1 $\left.\mathrm{N} \mathrm{m}^{-2}\left(10^{4} \mathrm{~km}\right)^{-1}\right]$. Summertime averages are removed from wind stress derivatives and the respective components of SST gradient in (c) and (d).

winds blowing from the Gulf of Mexico and Caribbean Sea toward the Pacific Ocean except through three lowelevation gaps in the Isthmus of Tehuantepec, in the Nicaragua lake district, and in Panama (Fig. 2c). Orographically induced low-level wind jets through these narrow mountain gaps are strongest during the boreal winter, reaching 10-20 $\mathrm{m} \mathrm{s}^{-1}$ with frequent gusts of $60 \mathrm{~m} \mathrm{~s}^{-1}$ (Stumpf 1975) and extending at least $500 \mathrm{~km}$ offshore into the Pacific Ocean (Roden 1961). The high-wind gap flows exert a strong influence on the mean geostrophic circulation and dynamics of the regional ocean, and thus are an imperative climatic ele- 

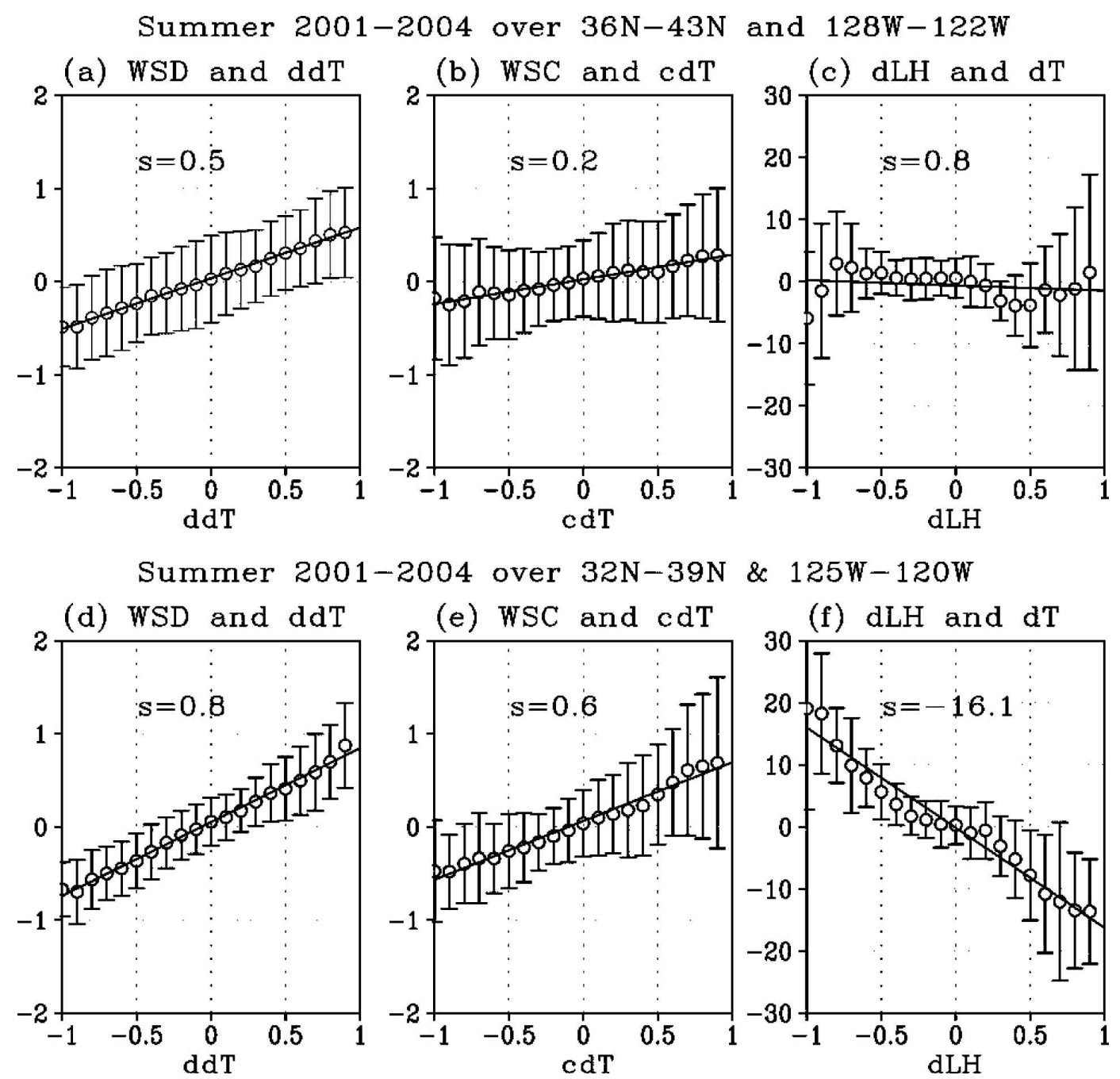

FIG. 11. Binned scatterplots over California coastal ocean computed from summertime (July-October) monthly averaged data from 2001 to 2004 over (a)-(c) $36^{\circ}-43^{\circ} \mathrm{N}, 128^{\circ}-122^{\circ} \mathrm{W}$ as used in Chelton et al. (2007), (d)-(e) $32^{\circ}-39^{\circ} \mathrm{N}, 125^{\circ}-120^{\circ} \mathrm{W}$. (a), (d) Wind stress divergence (WSD) $\left[\mathrm{N} \mathrm{m}^{-2}\left(10^{4} \mathrm{~km}\right)^{-1}\right]$ and downwind SST gradient $(\mathrm{ddT})\left[{ }^{\circ} \mathrm{C}(100 \mathrm{~km})^{-1}\right],(\mathrm{b}),(\mathrm{e})$ wind stress curl (WSC) $\left[\mathrm{N} \mathrm{m}^{-2}\left(10^{4} \mathrm{~km}\right)^{-1}\right]$ and crosswind SST gradient $(\mathrm{cdT})\left[{ }^{\circ} \mathrm{C}\right.$ $\left.(100 \mathrm{~km})^{-1}\right]$, and (c), (f) latent heat flux gradient $(d \mathrm{LH})\left[\mathrm{W} \mathrm{m}^{-2}\left(10^{4} \mathrm{~km}\right)^{-1}\right]$ and SST gradient $(d T)\left[{ }^{\circ} \mathrm{C}(100\right.$ $\mathrm{km})^{-1}$. Daily SST on the 7-km ROMS grid and atmospheric flux on the 16-km RSM grid were monthly averaged and smoothed using $0.5^{\circ}$ block averages. The SST gradient was computed from the resultant smoothed SST with centered differences. The derivatives of wind stress and heat flux were computed from the unsmoothed wind. The binned scatters were computed based on monthly averaged data for summertime. Large-scale summertime mean SST and wind stress are subtracted from full fields in (a), (b), (d), and (e).

ment of the eastern Pacific Ocean, establishing a distinctively different climate regime in the eastern Pacific than the central and western Pacific (Kessler 2002).

The gap winds are historically of great interest. Hurd (1929a,b) and Parmenter (1970) both observed arched squall lines and the formation of dense fog associated with the northerly wind of the Tehuantepec. Overland and Walter (1981) noted that these winds are driven by the along-gap pressure gradient. Numerous studies have investigated the structure and evolution of the gap winds (e.g., Schultz et al. 1997; Steenburgh et al. 1998; Chelton et al. 2000a,b), while others have examined their impacts on the regional ocean circulation (McCreary et al. 1989; Kessler 2002), upwelling and formation of stationary or propagating eddies (e.g., Roden 1961; Stumpf 1975; Stumpf and Legeckis 1977; Trasviña et al. 1995; Palacios and Bograd 2005), and the oceanic ecosystem (Fiedler 1994 2002).

Recently, Xie et al. (2005) focused on the Papagayo jet, whose zonal orientation and resulting band of Ek- 
man pumping on its southern flank yield far more important influence on the thermocline topography of the ocean than the Tehuantepec jet. In addition to jetinduced Ekman pumping in the wintertime, the positive wind stress curl on the southern flank of the Papagayo jet remains fairly strong throughout the year. This is maintained with the aid of large-scale atmospheric flow as the cross-equatorial southerly wind curves eastward and supplies additional background cyclonic wind shear. It results in a permanent shoaling of the thermocline called the Costa Rica Dome, centered at $9^{\circ} \mathrm{N}$ and $90^{\circ} \mathrm{W}$, where the mean depth of the $20^{\circ} \mathrm{C}$ isotherm is less than only $30 \mathrm{~m}$ (see Fig. 2 of Kessler 2002). Kessler (2002) noted that a linear Sverdrup balance forced by the enhanced positive Ekman pumping could explain the dynamic topography of the cyclonic Costa Rica Dome. Xie et al. (2005) explained that the zonal orientation of the Papagayo jet is responsible for the thermocline response, as the effect of Ekman pumping is accumulated westward from the coast in the zonal integral of the Sverdrup relation. The meridionally oriented Tehuantepec jet, on the other hand, permits eastwest canceling of Ekman forcing in the zonal integral, thus leaving only marginal impact on the dynamic topography in the wintertime.

Xie et al. (2005) subsequently revealed an important ocean-atmosphere feedback process involving the Costa Rica Dome and seasonal precipitation. The isolated cold spot at the sea surface, which is the surface expression of the Costa Rica Dome, leaves a marked impact on atmospheric deep convection in summer by generating a regional rainfall deficit within the intertropical convergence zone (ITCZ). The goal of the next section is to examine how well the SCOAR Model reproduces the observed mean climate and ocean-atmosphere coupling processes on seasonal time scales in the $\mathrm{CAC}$ region.

\section{2) Results}

As a test of the coupled model in the CAC domain, we performed a 5-yr (1999-2003) coupled model simulation with RA2 forcing to investigate the air-sea interactions associated with the gap winds (Fig. 2c; Table 1). This 5-yr period corresponds to the time period studied by Xie et al. (2005), which facilitates the direct comparison with the observations. Figures 12a,c show the seasonal climatology of wind stress vectors and their magnitudes. Prevailing easterlies are seen on the east coast of Central America and over the Gulf of Mexico. The gap-forced wind jets are well defined in the surface wind stress fields, exhibiting pronounced gap outflows off the coast of the three gaps. Figures $12 b, d$ illustrate the Ekman pumping velocity generated by these low- level wind jets, clearly showing that they force upwelling (downwelling) on the left (right) flank of the jets. Seasonal gap winds, and the corresponding curlinduced upwelling and downwelling, become stronger in the wintertime when the gap winds are more frequent.

Xie et al. (2005) suggest that Tehuantepec and Papagayo wind jets and the resultant vorticity forcings remain strong in their summer climatology. The present model displays only a slight hint of these summertime low-level winds, indicating a model deficiency. Nevertheless there is an indication of the patterns of alternating upwelling and downwelling along the coast during summertime within the ITCZ-induced broad band of upwelling (Fig. 12d).

These low-level wind jets exert a distinctive impact on the underlying SST fields. Figures 13a,c show the climatology of model SST, where the distinct minima off the three gaps that intensify in winter are illustrated. These cold regions are a direct response to mixing by wind gusts and associated Ekman upwelling that shoal the model thermocline (not shown). Comparing with the observations (Xie et al. 2005), in boreal winter the cold tongue off the Gulf of Tehuantepec is too warm while two other ones to the south are too cold. The surface expression of the Costa Rica Dome tends to be exaggerated in the model during both seasons, indicating that the model suffers a significant cold bias in the warm pool region (Figs. 3a,c).

The SCOAR simulation supports the Xie et al. (2005) hypothesis of the feedback of SST on summertime precipitation by qualitatively reproducing a similar precipitation climatology (Figs. 13b,d). Over the Costa Rica Dome, SST is colder by $2^{\circ} \mathrm{C}$ beyond its periphery. The SST colder than the convective threshold suppresses precipitation, producing a region of rainfall deficit within the ITCZ. This "dry hole" in the model is, however, only $\sim 300 \mathrm{~km}$ in diameter, which is smaller than the $\sim 500 \mathrm{~km}$ pattern apparent in observations.

It is worth noting that gap winds and air-sea interaction are also allowed in the ETP case since it includes the CAC domain, but with only half the horizontal resolution (Table 1). Interestingly, the dry hole was not visually evident in the ITCZ in this coarser-resolution run (not shown). This result is consistent with the study by Xie et al. (2007), in which a $0.5^{\circ}$ resolution coupled model was not able to produce the observed dry hole.

\section{Summary and discussion}

The SCOAR model, which combines two wellknown ocean (ROMS) and atmosphere (RSM) models with a flux coupling strategy, was developed to study 


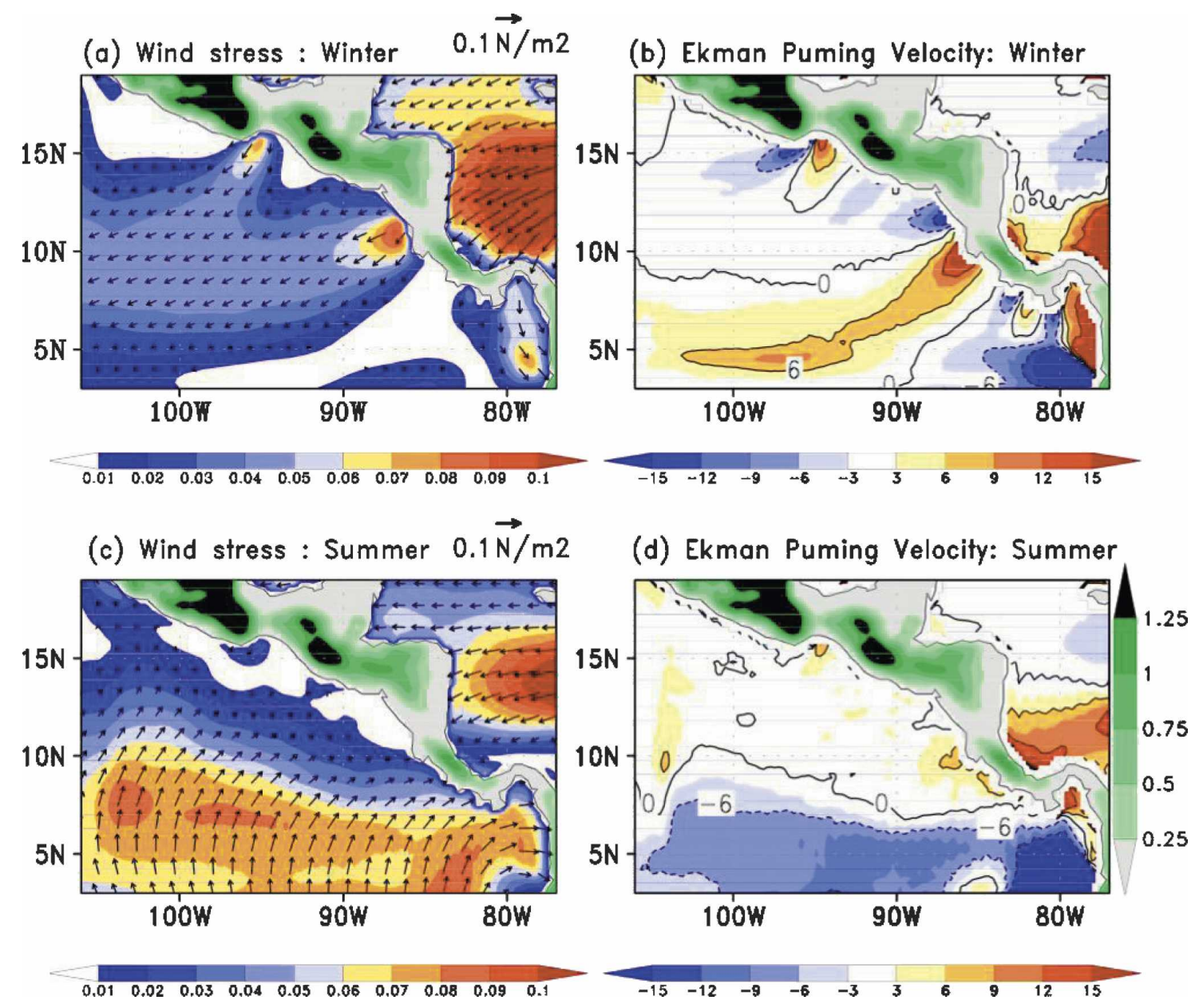

FIG. 12. (a), (c) Model climatology (1999-2003) of wind stress (WS) vector and magnitude ( $\mathrm{N} \mathrm{m}^{-2}$ ) averaged from (a) January to April (winter) and (c) July to October (summer). (b), (d) Wind-induced Ekman pumping velocity $\left(w_{e}, 10^{-6} \mathrm{~m} \mathrm{~s}^{-1}\right)$ exerted by gap winds for (b) winter and (d) summer.

small-scale coupled interactions. Its capabilities are demonstrated for three phenomena in three domains of the eastern Pacific Ocean: tropical instability waves in the eastern tropical Pacific, mesoscale eddies in the California Current System, and gap winds along the Central American coast. These phenomena are modeled here for the first time using high resolution and full coupling, with key aspects of model variables compared favorably with observations.

In the eastern tropical Pacific region, the SCOAR Model reproduces key features of observed air-sea coupling involving TIWs and cross-equatorial winds. Stability within the ABL changes as the surface winds blow across the front (Wallace et al. 1989). This results in acceleration of surface winds and enhanced turbulent heat flux over warmer SST to the north. The heat flux response yields thermodynamic feedback to the TIWs by enhancing (reducing) evaporative and sensible cooling of warmer (colder) water. This is consistent with numerous studies, which suggest that the feedback of turbulent and radiative flux on SST is negative, suppressing the growth of SST by TIWs (e.g., Deser et al. 1993; Thum et al. 2002).

In addition to the negative heat flux feedback from the perturbed atmosphere, TIWs induce a dynamic feedback from the atmosphere by generating narrow bands of strong wind stress curl and divergence along the SST fronts. In idealized experiments, Pezzi et al. (2004) found that active wind stress coupling modified by the underlying SST results in a slight decrease in TIW variability. Additional experiments using SCOAR with and without the effects of thermodynamic and dynamic feedbacks in this region are now in progress to address the role of each type of atmospheric feedback with TIWs.

In the CCS region, a similar linear relationship between derivatives of SST and wind stress was also identified in monthly averaged model outputs. Wind stress 
(a) SST: Winter

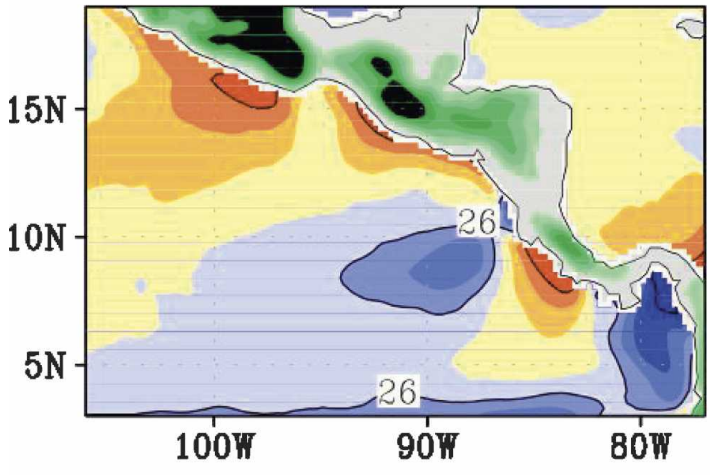

$\begin{array}{lllllllllll}24 & 24.5 & 25 & 25.5 & 26 & 26.5 & 27 & 27.5 & 28 & 28.5 & 29\end{array}$

(c) SST: Summer

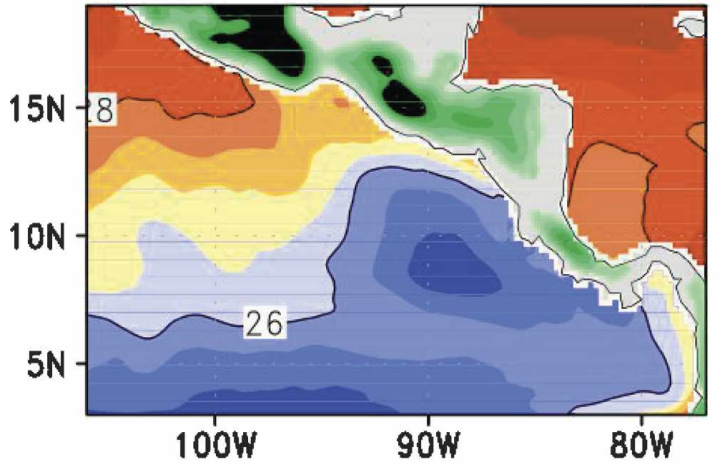

$\begin{array}{lllllllllll}24 & 24.5 & 25 & 25.5 & 26 & 26.5 & 27 & 27.5 & 28 & 28.5 & 29\end{array}$ (b) Rainfall: Winter

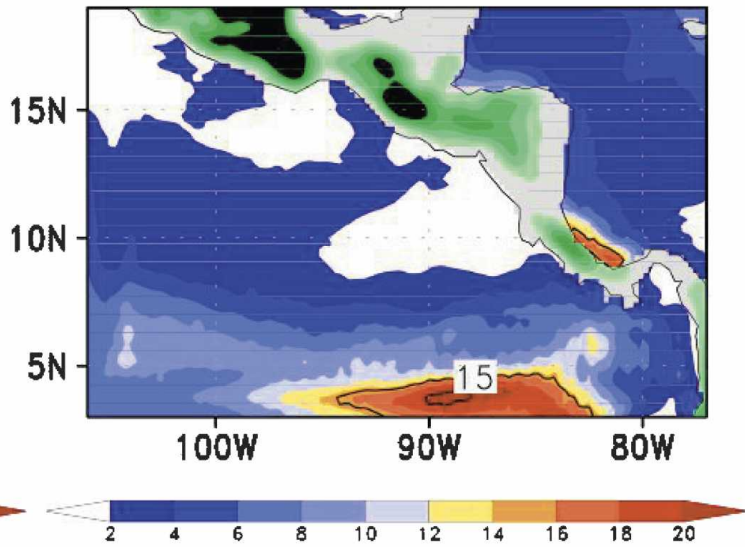

(d) Rainfall: Summer

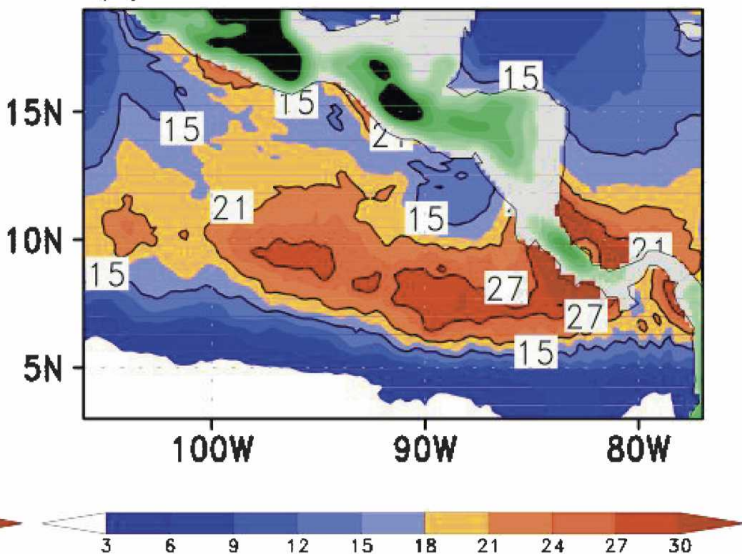

FIG. 13. As in Fig. 12 except for (a), (c) SST $\left({ }^{\circ} \mathrm{C}\right)$. Corresponding precipitation (mm day $\left.{ }^{-1}\right)$ is shown (b) for winter and (d) for summer. Note that color scale is different in (b) and (d) to better display the precipitation patterns in the different seasons.

curl and divergence are linearly proportional to the crosswind and downwind SST gradient near the coastal ocean. However, the linear slopes computed from the scatterplots are weaker than observed (Chelton et al. 2007), perhaps due to the discrepancy between the model climatology and observations or to the resolution limitations of the satellite SST data. A closer examination of SST-induced perturbation of wind stress curl and the subsequent impact on the open ocean dynamics is currently underway using SCOAR.

Along the west coast of Central America, coupled feedbacks involving coastal mountains, low-level wind jets, thermocline topography, and precipitation are replicated on seasonal time scales. Despite discrepancies in the intensity of Ekman forcing by wind jets, the extent of the Costa Rica Dome, and the size of the dry hole within the ITCZ, the model reproduces the seasonal climatology in this region reasonably well. Most importantly, the SCOAR Model captures the key features of ocean-atmosphere feedback between the surface expression of the Costa Rica Dome and the dry hole in the ITCZ.

These preliminary results motivate further studies of these and other coupled ocean-atmosphere phenomena that occur around the globe. A key modeling strategy will involve comparing simulations in fully coupled, partially coupled, and uncoupled modes. By introducing and adjusting the coupling parameters of the thermodynamic and dynamic interaction of the air and sea, one can address fundamental questions on the role of the ocean-induced atmospheric feedbacks to the ocean anomalies, and the relative importance of the thermodynamic and dynamic feedbacks. Detailed analyses are in progress.

Acknowledgments. This work forms a part of the Ph.D. dissertation of HS. We gratefully acknowledge funding support from NOAA (NA17RJ1231 through 
ECPC and CORC), DOE (DE-FG02-04ER63857), ONR (N00014-05-1-0363), NSF (OCE0121332), and NASA (NNH04ZYS008N). The views expressed herein are those of the authors and do not necessarily reflect the views of these agencies. We thank Dr. Masao Kanamitsu, Prof. Emanuele Di Lorenzo, Prof. Raghu Murtugudde, Dr. Markus Jochum, Prof. Shang-Ping Xie, Dr. Guillermo Auad, Dr. Hideki Kanamaru, Dr. Larry O'Neill and Mr. Akihiko Shimpo for their important discussions. We also thank Prof. Dudley Chelton and two anonymous reviewers for providing extensive comments and suggestions that significantly improved the manuscript.

\section{REFERENCES}

Aldrian, E., D. V. Sein, D. Jacob, L. D. Gates, and R. Podzun, 2005: Modeling Indonesian rainfall with a coupled regional model. Climate Dyn., 25, 1-17.

Allen, J. S., 1980: Models of wind-driven currents on the continental shelf. Аnnu. Rev. Fluid Mech., 12, 389-433.

Arakawa, A., and W. H. Schubert, 1974: Interaction of a cumulus cloud ensemble with the large-scale environment, Part I. $J$. Atmos. Sci., 31, 674-701.

Bao, J.-W., J. M. Wilczak, J.-K. Choi, and L. H. Kantha, 2000: Numerical simulations of air-sea interactions under high wind conditions using a coupled model: A study of hurricane development. Mon. Wea. Rev., 128, 2190-2210.

Baturin, N. G., and P. P. Niiler, 1997: Effects of instability waves in the mixed layer of the equatorial Pacific. J. Geophys. Res., 102, 27 771-27 794.

Behringer, D., L. Regier, and H. Stommel, 1979: Thermal feedback on wind stress as a contributing cause of the Gulf Stream. J. Mar. Res., 37, 699-709.

Bender, M. A., and I. Ginis, 2000: Real-case simulations of hurricane-ocean interaction using a high-resolution coupled model: Effects on hurricane intensity. Mon. Wea. Rev., 128, 917-946.

Bye, J. A. T., 1986: Momentum exchange at the sea surface by wind stress and understress. Quart. J. Roy. Meteor. Soc., 112, 501-510.

Castelao, R. M., T. P. Mavor, J. A. Barth, and L. C. Breaker, 2006: Sea surface temperature fronts in the California Current System from geostationary satellite observations. J. Geophys. Res., 111, C09026, doi:10.1029/2006JC003541.

Chelton, D. B., 2005: The impact of SST specification on ECMWF surface wind stress fields in the eastern tropical Pacific. $J$. Climate, 18, 530-550.

— and M. H. Freilich, 2005: Scatterometer-based assessment of $10-\mathrm{m}$ wind analyses from the operational ECMWF and NCEP numerical weather prediction models. Mon. Wea. Rev., 133, 409-429.

— , and F. J. Wentz, 2005: Global microwave satellite observations of sea surface temperature for numerical weather prediction and climate research. Bull. Amer. Meteor. Soc., 86, 1097-1115.

— M. H. Freilich, and S. N. Esbensen, 2000a: Satellite observations of the wind jets off the Pacific coast of Central America. Part I: Case studies and statistical characteristics. Mon. Wea. Rev., 128, 1993-2018.

$\_,-$, and $\_, 2000 \mathrm{~b}$ : Satellite observations of the wind jets off the Pacific coast of Central America. Part II: Regional relationships and dynamic considerations. Mon. Wea. Rev., 128, 2019-2043.

— , F. J. Wentz, C. L. Gentemann, R. A. de Szoeke, and M. G. Schlax, 2000c: Satellite microwave SST observations of transequatorial tropical instability waves. Geophys. Res. Lett., 27, 1239-1242.

_ - and Coauthors, 2001: Observations of coupling between surface wind stress and sea surface temperature in the eastern tropical Pacific. J. Climate, 14, 1479-1498.

—, M. G. Schlax, M. H. Freilich, and R. F. Milliff, 2004: Satellite measurements reveal persistent small-scale features in ocean winds. Science, 303, 978-983.

,-- , and R. M. Samelson, 2007: Summertime coupling between sea surface temperature and wind stress in the California Current System. J. Phys. Oceanogr., in press.

Chen, S. S., W. Zhao, M. A. Donelan, J. F. Price, E. J. Walsh, T. B. Sanford, and H. L. Tolman, 2007: The CBLASThurricane program and the next-generation fully coupled atmosphere-wave-ocean models for hurricane research and prediction. Bull. Amer. Meteor. Soc., in press.

Cornillon, P., and K.-A. Park, 2001: Warm core ring velocities inferred from NSCAT. Geophys. Res. Lett., 28, 575-578.

Cox, M. D., 1980: Generation and propagation of 30-day waves in a numerical model of the Pacific. J. Phys. Oceanogr., 10, 1168-1186.

Cronin, M. F., N. A. Bond, C. Fairall, J. Hare, M. J. McPhaden, and R. A. Weller, 2002: Enhanced oceanic and atmospheric monitoring underway in eastern Pacific. Eos, Trans. Amer. Geophys. Union, 83, 210-211.

Dawe, J. T., and L. Thompson, 2006: The effect of ocean surface currents on wind stress, heat flux, and wind power input to the ocean. Geophys. Res. Lett., 33, L09604, doi:10.1029/ 2006GL025784.

Deser, C., J. J. Bates, and S. Wahl, 1993: The influence of sea surface temperature gradients on stratiform cloudiness along the equatorial front in the Pacific Ocean. J. Climate, 6, 11721180.

de Szoeke, S. P., and C. S. Bretherton, 2004: Quasi-Lagrangian large eddy simulations of cross-equatorial flow in the east Pacific atmospheric boundary layer. J. Atmos. Sci., 61, 18371858.

,- , N. A. Bond, M. F. Cronin, and B. M. Morley, 2005: EPIC $95^{\circ} \mathrm{W}$ observations of the eastern Pacific atmospheric boundary layer from the cold tongue to the ITCZ. J. Atmos. Sci., 62, 426-442.

Di Lorenzo, E., 2003: Seasonal dynamics of the surface circulation in the southern California Current System. Deep-Sea Res. II, 50, 2371-2388.

_ A. J. Miller, N. Schneider, and J. C. McWilliams, 2005: The warming of the California Current System: Dynamics and ecosystem implications. J. Phys. Oceanogr., 35, 336-362.

Döscher, R., U. Willén, C. Jones, A. Rutgersson, H. E. M. Meier, U. Hansson, and L. P. Graham, 2002: The development of the regional coupled ocean-atmosphere model RCAO. Boreal Environ. Res., 7, 183-192.

Duhaut, T. H. A., and D. N. Straub, 2006: Wind stress dependence on ocean surface velocity: Implications for mechanical energy input to ocean circulation. J. Phys. Oceanogr., 36, 202-211.

Fairall, C. W., E. F. Bradley, D. P. Rogers, J. B. Edson, and G. S. Young, 1996: Bulk parameterization of air-sea fluxes for Tropical Ocean Global Atmosphere Coupled-Ocean Atmosphere Response Experiment. J. Geophys. Res., 101, 3747-3764. 
Fiedler, P. C., 1994: Seasonal and interannual variability of coastal zone color scanner phytoplankton pigments and winds in the eastern tropical Pacific. J. Geophys. Res., 99, 18 371-18 384.

_ 2002: The annual cycle and biological effects of the Costa Rica Dome. Deep-Sea Res. I, 49, 321-338.

Gustafsson, N., L. Nyberg, and A. Omstedt, 1998: Coupling of a high-resolution atmospheric model and an ocean model for the Baltic Sea. Mon. Wea. Rev., 126, 2822-2846.

Haack, T., S. D. Burk, and R. M. Hodur, 2005: U.S. West Coast surface heat fluxes, wind stress, and wind stress curl from a mesoscale model. Mon. Wea. Rev., 133, 3202-3216.

Hagedorn, R., A. Lehmann, and D. Jacob, 2000: A coupled high resolution atmosphere-ocean model for the BALTEX region. Meteor. Z., 9, 7-20.

Haidvogel, D. B., H. G. Arango, K. Hedstrom, A. Beckmann, P. Malanotte-Rizzoli, and A. F. Shchepetkin, 2000: Model evaluation experiments in the North Atlantic basin: Simulations in nonlinear terrain-following coordinates. Dyn. Atmos. Oceans, 32, 239-281.

Hansen, D., and C. A. Paul, 1984: Genesis and effects of long waves in the equatorial Pacific. J. Geophys. Res., 89, $10431-$ 10440.

Hashizume, H., S.-P. Xie, W. T. Liu, and K. Takeuchi, 2001: Local and remote atmospheric response to tropical instability waves: A global view from space. J. Geophys. Res., 106, 10 173-10 185

,-- M. Fujiwara, M. Shiotani, T. Watanabe, Y. Tanimoto, W. T. Liu, and K. Takeuchi, 2002: Direct observations of atmospheric boundary layer response to SST variations associated with tropical instability waves over the eastern equatorial Pacific. J. Climate, 15, 3379-3393.

Hayes, S. P., M. J. McPhaden, and J. M. Wallace, 1989: The influence of sea surface temperature on surface wind in the eastern equatorial Pacific: Weekly to monthly variability. J. Climate, 2, 1500-1506.

Hickey, B. M., 1979: The California Current System-Hypothesis and facts. Progress in Oceanography, Vol. 8, Pergamon, 191279

Hong, S.-Y., and H.-L. Pan, 1996: Nonlocal boundary layer vertical diffusion in a medium-range forecast model. Mon. Wea. Rev., 124, 2322-2339.

Huang, B., P. S. Schopf, and J. Shukla, 2004: Intrinsic oceanatmosphere variability of the tropical Atlantic Ocean. J. Climate, 17, 2058-2077.

Hurd, W. E., 1929a: Fog in the Gulf of Tehuantepec, November 1929. Mon. Wea. Rev., 57, 485.

_ 1929b: Northers of the Gulf of Tehuantepec. Mon. Wea. Rev., 57, 192-194.

Jochum, M., and R. Murtugudde, 2006: Temperature advection by tropical instability waves. J. Phys. Oceanogr., 36, 592-605.

Juang, H.-M. H., and M. Kanamitsu, 1994: The NMC nested regional spectral model. Mon. Wea. Rev., 122, 3-26.

_ - S.-Y. Hong, and M. Kanamitsu, 1997: The NCEP regional spectral model: An update. Bull. Amer. Meteor. Soc., 78, 2125-2143.

Kanamitsu, M., W. Ebisuzaki, J. Woolen, J. Potter, and M. Fiorino, 2002a: NCEP-DOE AMIP-II Reanalysis (R-2). Bull. Amer. Meteor. Soc., 83, 1631-1643.

— system 2000. Bull. Amer. Meteor. Soc., 83, 1019-1037.

Kelly, K. A., S. Dickinson, M. J. McPhaden, and G. C. Johnson, 2001: Ocean currents evident in satellite wind data. Geophys. Res. Lett., 28, 2469-2472.
Kessler, W. S., 2002: Mean three-dimensional circulation in the northeast tropical Pacific. J. Phys. Oceanogr., 32, 2457-2471.

-, G. C. Johnson, and D. W. Moore, 2003: Sverdrup and nonlinear dynamics of the Pacific equatorial currents. J. Phys. Oceanogr., 33, 994-1008.

Large, W. G., J. C. McWilliams, and S. C. Doney, 1994: Oceanic vertical mixing: A review and a model with a nonlocal boundary layer parameterization. Rev. Geophys., 32, 363-404.

Legeckis, R., 1977: Long waves in the eastern equatorial Pacific Ocean: A view from a geostationary satellite. Science, 197, 1177-1181.

_ W. Pichel, and G. Nesterczuk, 1983: Equatorial long waves in geostationary satellite observations and in a multichannel sea surface temperature analysis. Bull. Amer. Meteor. Soc., 64, 133-139.

Levitus, S., and T. P. Boyer, 1994: Temperature. Vol. 4, World Ocean Atlas 1994, NOAA Atlas NESDIS 4, 117 pp.

—, R. Burgette, and T. P. Boyer, 1994: Salinity. Vol. 3, World Ocean Atlas 1994, NOAA Atlas NESDIS 3, 99 pp.

Li, Y., and H. Xue, 2002: Air-sea interactions during the passage of a winter storm over the Gulf Stream: A three-dimensional coupled atmosphere-ocean model study. J. Geophys. Res., 107, 3200, doi:10.1029/2001JC001161.

Liu, W. T., X. Xie, P. S. Polito, S. P. Xie, and H. Hashizume, 2000: Atmospheric manifestation of tropical instability waves observed by QuikSCAT and Tropical Rain Measuring Mission. Geophys. Res. Lett., 27, 2545-2548.

Loglisci, N., and Coauthors, 2004: Development of an atmosphere-ocean coupled model and its application over the Adriatic Sea during a severe weather event of bora wind. $J$. Geophys. Res., 109, D01102, doi:10.1029/2003JD003956.

Luo, J.-J., S. Masson, E. Roeckner, G. Madec, and T. Yamagata, 2005: Reducing climatology bias in an ocean-atmosphere CGCM with improved coupling physics. J. Climate, 18, 23442360.

Lynn, R. J., and J. J. Simpson, 1987: The California Current System: The seasonal variability of its physical characteristics. $J$. Geophys. Res., 92, 12 947-12 966.

Marchesiello, P., J. C. McWilliams, and A. Shchepetkin, 2001: Open boundary conditions for long-term integration of regional oceanic models. Ocean Modell., 3, 1-20.

$\ldots, \ldots$, and _ _ 2003: Equilibrium structure and dynamics of the California Current System. J. Phys. Oceanogr., 33, 753783.

McCreary, J. P., Jr., H. S. Lee, and D. B. Enfield, 1989: The response of the coastal ocean to strong offshore winds: With application to circulations in the Gulfs of Tehuantepec and Papagayo. J. Mar. Res., 47, 81-109.

Mikolajewicz, U., D. V. Sein, D. Jacob, T. Konigk, R. Pozdun, and T. Semmler, 2005: Simulating Arctic sea ice variability with a coupled regional atmosphere-ocean-sea ice model. Meteor. Z., 14, 793-800.

Moore, A. M., H. G. Arango, E. Di Lorenzo, D. B. Cornuelle, A. J. Miller, and D. J. Nielson, 2004: A comprehensive ocean prediction and analysis system based on the tangent linear and adjoint of a regional ocean model. Ocean Modell., 7, $227-258$.

Moorthi, S., and M. J. Suarez, 1992: Relaxed Arakawa-Schubert: A Parameterization of moist convection for general circulation models. Mon. Wea. Rev., 120, 978-1002.

Nonaka, M., and S.-P. Xie, 2003: Covariations of sea surface temperature and wind over the Kurishio and its extension: Evi- 
dence for ocean-to-atmosphere feedback. J. Climate, 16, 1404-1413.

O'Neill, L. W., D. B. Chelton, S. K. Esbensen, and F. J. Wentz, 2005: High-resolution satellite measurements of the atmospheric boundary layer response to SST variations along the Agulhas Return Current. J. Climate, 18, 2706-2723.

Overland, J. E., and B. A. Walter Jr., 1981: Gap winds in the Strait of Juan de Fuca. Mon. Wea. Rev., 109, 2221-2233.

Palacios, D. M., and S. J. Bograd, 2005: A census of Tehuantepec and Papagayo eddies in the northeastern tropical Pacific. Geophys. Res. Lett., 32, L23606, doi:10.1029/2005GL024324.

Park, K.-A., P. Cornillon, and D. L. Codiga, 2006: Modification of surface winds near ocean fronts: Effects of Gulf Stream rings on scatterometer (QuikSCAT, NSCAT) wind observations. J. Geophys. Res., 111, C03021, doi:10.1029/2005JC003016.

Parmenter, F. C., 1970: Picture of the month: A "Tehuantepecer." Mon. Wea. Rev., 98, 479-479.

Perlin, N., R. M. Samelson, and D. B. Chelton, 2004: Scatterometer and model wind and wind stress in the Oregon-northern California coastal zone. Mon. Wea. Rev., 132, 2110-2129.

Perrie, W., X. Ren, W. Zhang, and Z. Long, 2004: Simulation of extratropical Hurricane Gustav using a coupled atmosphereocean-sea spray model. Geophys. Res. Lett., 31, L03110, doi:10.1029/2003GL018571.

Pezzi, L. P., J. Vialard, K. J. Richard, C. Menkes, and D. Anderson, 2004: Influence of ocean-atmosphere coupling on the properties of tropical instability waves. Geophys. Res. Lett., 31, L16306, doi:10.1029/2004GL019995.

Philander, S. G. H., 1976: Instabilities of zonal equatorial currents. J. Geophys. Res., 81, 3725-3735.

_ 1978: Instabilities of zonal equatorial currents, 2. J. Geophys. Res., 83, 3679-3682.

Pickett, M. H., and J. D. Paduan, 2003: Ekman transport and pumping in the California Current based on the U.S. Navy's high-resolution atmospheric model (COAMPS). J. Geophys. Res., 108, 3327, doi:10.1029/2003JC001902.

Powers, J. G., and M. T. Stoelinga, 2000: A coupled air-sea mesoscale model: Experiments in atmospheric sensitivity to marine roughness. Mon. Wea. Rev., 128, 208-228.

Pullen, J., J. D. Doyle, and R. P. Signell, 2006: Two-way air-sea coupling: A study of the Adriatic. Mon. Wea. Rev., 134, 14651483.

Qiao, L., and R. H. Weisberg, 1998: Tropical instability waves energetics: Observations from the Tropical Instability Wave Experiment. J. Phys. Oceanogr., 28, 345-360.

Raymond, D. J., S. K. Esbensen, M. Gregg, and C. S. Bretherton, 2004: EPIC 2001 and the coupled ocean-atmosphere system of the tropical east Pacific. Bull. Amer. Meteor. Soc., 85, $1341-1354$.

Ren, X., and Y. Qian, 2005: A coupled regional air-sea model, its performances and climate drift in simulation of the east Asian summer monsoon in 1998. Int. J. Climatol., 25, 679692.

Roads, J. O., S.-C. Chen, and M. Kanamitsu, 2003: U.S. regional climate simulations and seasonal forecasts. J. Geophys. Res., 108, 8606, doi:10.1029/2002JD002232.

Roden, G. I., 1961: On the wind-driven circulation in the Gulf of Tehuantepec and its effect upon surface temperatures. Geofis. Int., 1, 55-72.

Sakamoto, T. T., A. Sumi, S. Emori, T. Nishimura, H. Hasumi, T. Suzuki, and M. Kimoto, 2004: Far-reaching effects on the Hawaiian Islands in the CCSR/NIES/FRCGC high-resolu- tion climate model. Geophys. Res. Lett., 31, L17212, doi:10.1029/2004GL020907.

Schrum, C., U. Hübner, D. Jacob, and R. Podzun, 2003: A coupled atmosphere/ice/ocean model for the North Sea and Baltic Sea. Climate Dyn., 21, 131-141.

Schultz, D. M., W. E. Bracken, L. F. Bosart, G. J. Hakim, M. A. Bedrick, M. J. Dickinson, and K. R. Tyle, 1997: The 1993 superstorm cold surge: Frontal structure, gap flow, and tropical impact. Mon. Wea. Rev., 125, 5-39.

Seo, H., M. Jochum, R. Murtugudde, and A. J. Miller, 2006: Effect of ocean mesoscale variability on the mean state of tropical Atlantic climate. Geophys. Res. Lett., 33, L09606, doi:10.1029/ 2005 GL025651.

Shchepetkin, A. F., and J. C. McWilliams, 2005: The regional oceanic modeling system (ROMS): A split-explicit, free-surface, topography-following-coordinate ocean model. Ocean Modell., 9, 347-404.

Small, R. J., S.-P. Xie, and Y. Wang, 2003: Numerical simulation of atmospheric response to Pacific tropical instability waves. J. Climate, 16, 3723-3741.

,,,--- S. K. Esbensen, and D. Vickers, 2005: Numerical simulation of boundary layer structure and cross-equatorial flow in the eastern Pacific. J. Atmos. Sci., 62, 1812-1830.

Steenburgh, W. J., D. M. Schultz, and B. A. Colle, 1998: The structure and evolution of gap outflow over the Gulf of Tehuantepec, Mexico. Mon. Wea. Rev., 126, 2673-2691.

Strub, P. T., and C. James, 2000: Altimeter-derived variability of surface velocities in the California Current System: 2. Seasonal circulation and eddy statistics. Deep-Sea Res. II, 47, 831-870.

Stumpf, H. G., 1975: Satellite detection of upwelling in the Gulf of Tehuantepec, Mexico. J. Phys. Oceanogr., 5, 383-388.

_ , and R. V. Legeckis, 1977: Satellite observations of mesoscale eddy dynamics in the eastern tropical Pacific Ocean. $J$. Phys. Oceanogr., 7, 648-658.

Sweet, W., R. Fett, J. Kerling, and P. La Violette, 1981: Air-sea interaction effects in the lower troposphere across the north wall of the Gulf Stream. Mon. Wea. Rev., 109, 1042-1052.

Thum, N., S. K. Esbensen, D. B. Chelton, and M. J. McPhaden, 2002: Air-sea heat exchange along the northern sea surface temperature front in the eastern tropical Pacific. J. Climate, 15, 3361-3378.

Trasviña, A., E. D. Barton, J. Brown, H. S. Velez, P. M. Kosro, and R. L. Smith, 1995: Offshore wind forcing in the Gulf of Tehuantepec, Mexico: The asymmetric circulation. J. Geophys. Res., 100, 20 649-20 663.

Vecchi, G. A., S.-P. Xie, and A. S. Fischer, 2004: Oceanatmosphere covariability in the western Arabian Sea. J. Climate, 17, 1213-1224.

Wallace, J. M., T. P. Mitchell, and C. Deser, 1989: The influence of sea surface temperature on surface wind in the eastern equatorial Pacific: Seasonal and interannual variability. $J$. Climate, 2, 1492-1499.

Wentz, F. J., and T. Meissner, 2000: Algorithm Theoretical Basis Document (ATBD), version 2: AMSR-E Ocean Algorithm, Remote Sensing Systems Tech. Rep. RSS 121599A-1, 55 pp.

- C. Gentemann, D. Smith, and D. Chelton, 2000: Satellite measurement of sea surface temperature through clouds. Science, 288, 847-850.

Wilkin, J. L., H. G. Arango, D. B. Haidvogel, C. S. Lichtenwalner, S. M. Glenn, and K. S. Hedström, 2005: A regional ocean modeling system for the Long-term Ecosystem Observatory. J. Geophys. Res., 110, C06S91, doi:10.1029/2003JC002218. 
Xie, S.-P., 2004: Satellite observations of cool ocean-atmosphere interaction. Bull. Amer. Meteor. Soc., 85, 195-209.

— - W. T. Liu, Q. Liu, and M. Nonaka, 2001: Far-reaching effects of the Hawaiian Islands on the Pacific ocean-atmosphere system. Science, 292, 2057-2060.

, H. Xu, W. S. Kessler, and M. Nonaka, 2005: Air-sea interaction over the eastern Pacific warm pool: Gap winds, thermocline dome, and atmospheric convection. J. Climate, 18, 5-20.
_ , and Coauthors, 2007: A regional ocean-atmosphere model for eastern Pacific climate: Toward reducing tropical biases. J. Climate, in press.

Yu, Z., J. P. McCreary Jr., and J. A. Proehl, 1995: Meridional asymmetry and energetics of tropical instability waves. $J$. Phys. Oceanogr., 25, 2997-3007.

Zhang, G. J., and M. J. McPhaden, 1995: The relationship between sea surface temperature and latent heat flux in the equatorial Pacific. J. Climate, 8, 589-605. 